\title{
Dehydra-Decyclization of 2-Methyltetrahydrofuran to Pentadienes on Boron-Containing Zeolites
}

\author{
Gaurav Kumar $\$$, Dongxia Liu ${ }^{\dagger}$, Dandan $\mathrm{Xu}^{\beta}$, Limin Ren $\$, \delta$, \\ Michael Tsapatsis ${ }^{\xi, g, *}$, Paul J. Dauenhauer,n,**
}

$\$$ Department of Chemical Engineering and Materials Science, University of Minnesota, 421 Washington Ave. SE, Minneapolis, MN 55455, USA

${ }^{\dagger}$ Department of Chemical and Biomolecular Engineering, University of Maryland, College Park, MD, 20742, USA

${ }^{\beta}$ Department of Chemical Engineering, University of Massachusetts Amherst, 686 N. Pleasant Street, Amherst, MA 01003, USA

${ }^{\delta}$ Zhang Dayu school of chemistry, Dalian university of technology, No. 2 Linggong Road, Dalian, China, 116024

${ }^{\xi}$ Department of Chemical and Biomolecular Engineering \& Institute for NanoBioTechnology, Johns Hopkins University, 3400 N. Charles Street, Baltimore, MD 21218, USA

${ }^{\mathrm{g}}$ Johns Hopkins University, Applied Physics Laboratory, 11100 Johns Hopkins Road, Laurel, MB 20723, USA

" Center for Sustainable Polymers, University of Minnesota, 207 Pleasant St. SE, Minneapolis, MN 55455, USA

*Corresponding authors: hauer@umn.edu, tsapatsis@jhu.edu

\begin{abstract}
Biomass-derived 2-methyltetrahydrofuran (2-MTHF) undergoes tandem ring-opening and dehydration (dehydra-decyclization) to linear pentadienes, namely 1,3-pentadiene and 1,4-pentadiene. It can also fragment to butenes and formaldehyde through a competing retro-Prins condensation pathway. Using detailed kinetic measurements of 2-MTHF dehydra-decyclization on zeolites with disparate acidities (boro-, and alumino-silicates) and micropore environments (MFI, MWW, and BEA), weakly acidic borosilicates were shown to exhibit ca. 10-30\% higher selectivity to dienes at about five-to-sixty times lower proton-normalized rates than aluminosilicates (453-573 K). Dehydra-decyclization site time yields (STYs) were invariant for aluminosilicates within the investigated frameworks, indicating the absence of pore-confinement influence. However, individual site-normalized reaction rates varied by almost an order of magnitude on borosilicates in the order MWW > MFI > BEA at a given temperature $(523 \mathrm{~K})$, indicating the different nature of active sites in these weak solid acids. The diene distribution remained far from equilibrium and was tuned towards the desirable conjugated diene (1,3-pentadiene) by facile isomerization of 1,4-pentadiene. This tuning capability was facilitated by high bed residence times, as well as the smaller micropore sizes among the considered zeolite frameworks. The suppression of competing pathways and promotion of 1,4-pentadiene isomerization events lead to a hitherto unreported $\sim 86 \%$ 1,3-pentadiene yield and an overall $\sim 89 \%$ combined linear C5 dienes' yield at near quantitative ( $98 \%)$ 2-MTHF conversion on the borosilicate B-MWW, without a significant reduction in diene selectivities for at least 80 hours time-on-stream under low space velocity $(0.85 \mathrm{~g}$ reactant/g cat./h) and high temperature ( $658 \mathrm{~K})$ conditions. Finally, starting with iso-conversion levels (ca. 21-26\%) and using total turnover numbers (TONs) accrued over the entire catalyst lifetime as the stability criterion, borosilicates were demonstrated to be significantly more stable than aluminosilicates under reaction conditions $(\sim 3-6 \mathrm{x}$ higher TONs).
\end{abstract}

1.0 Introduction. Conjugated $\mathrm{C} 4-\mathrm{C} 5$ dienes, currently manufactured as a byproduct of the cracking of naphtha and gas oil fraction of crude oil, are vital bulk chemicals for the elastomer industry. ${ }^{[1,2]}$ Due to a recent surge in the supply of shale-gas ethane, refineries are finding ways to decouple the production of ethylene and $\mathrm{C} 4-\mathrm{C} 5$ fractions including isoprene, butadiene, and piperylene (1,3-pentadiene), accentuating the need to produce these chemicals from alternative onpurpose routes possibly utilizing renewable feedstocks such as lignocellulosic biomass. ${ }^{[3,4,5,6]}$ While isoprene is understandably the most valuable C5 diene isomer, 1,3-pentadiene has recently 

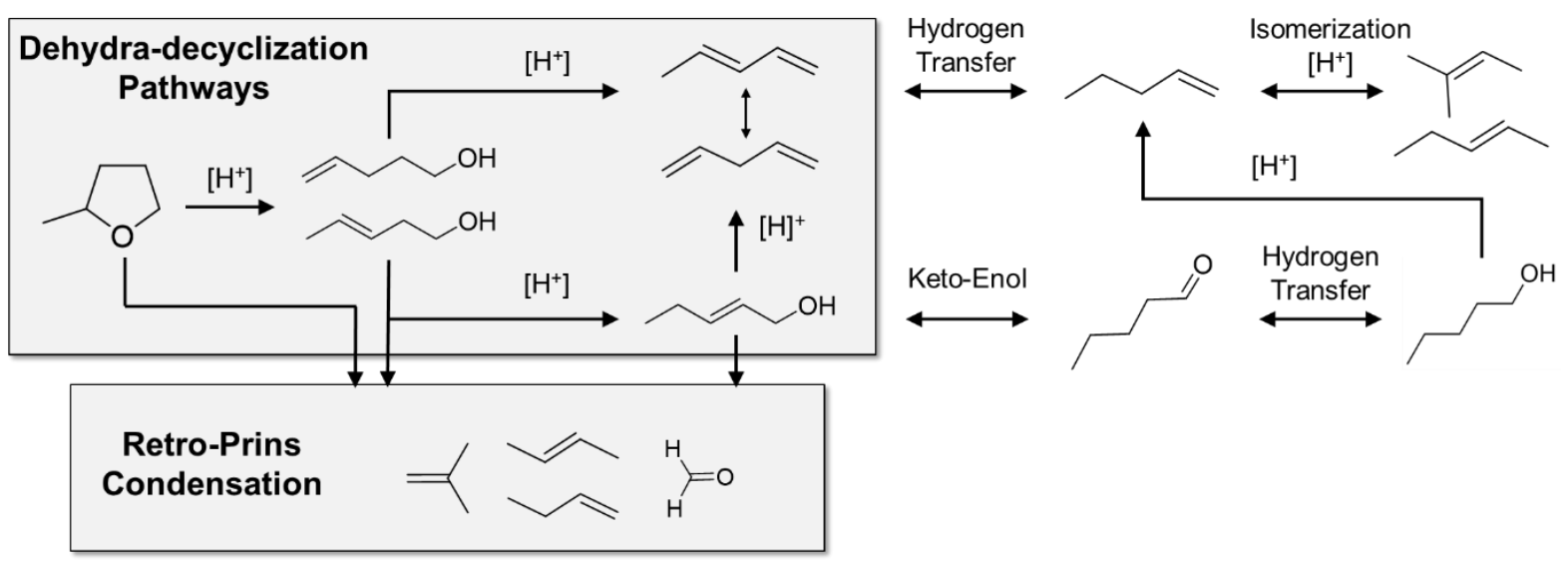

Scheme 1. Reaction pathways for the conversion of 2-MTHF over solid Brønsted acids ${ }^{[11,12,37,87-89]}$.

attracted attention as a high potential feedstock for fine chemical synthesis using transition metal catalysis. ${ }^{[7,8,9,10]}$

We previously reported a thermochemical route (Scheme 1) to 1,3-butadiene, 1,3-pentadiene, and isoprene from the vapor-phase dehydradecyclization of biomass-derived saturated fivemembered cyclic ethers tetrahydrofuran (THF), 2methyltetrahydrofuran (2-MTHF), and 3methyltetrahydrofuran (3-MTHF), respectively. ${ }^{[11,12]}$ These studies reported high selectivity to corresponding dienes on phosphoruscontaining all-silica zeolites. However, the nature of active sites and the surrounding silica framework in these materials remains nebulous. ${ }^{[13,14]}$ Cho et al. reported the inability of these sites to catalyze 2propylamine Hoffman elimination and to protonate pyridine ${ }^{[14]}$ Most recently, Gorte and co-workers have reported the onset temperature of H-D exchange of toluene on phosphorous-containing self-pillared pentasil (P-SPP) to be $\geq 100 \mathrm{~K}$ higher than aluminosilicates, highlighting the weakly acidic nature of these materials. ${ }^{[15]}$ It is also important to note that these phosphorous active sites are distinctly different from the well-studied Brønsted acid sites in silicoaluminophosphates (commonly known as SAPO zeotypes) $;{ }^{[16,17,18]}$ the $\mathrm{P}-\mathrm{OH}$ functionalities on aluminum-free all-silica support in P-zeosils are significantly weaker. Based on these observations, the role of acid site strength on dehydra-decyclization was considered on solid Brønsted acids with relatively wellunderstood active sites that are weaker than bridged hydroxyls in aluminosilicates.

The tuning of Brønsted acidic site strength has been implemented in zeolites by incorporating different trivalent atoms in the framework. ${ }^{[19,20,21,22]}$ Iglesia and co-workers have reported deprotonation energy (DPE) determined from periodic density functional theory calculations as a measure of the acidic strength of microporous solid acids. ${ }^{[23]}$ Furthermore, the same group has shown the effect of heteroatoms like $\mathrm{Al}^{3+}, \mathrm{B}^{3+}$, and $\mathrm{Ga}^{3+}$ in MFI framework on DPE values, indicating that the acid site strength among heteroatom-substituted zeolites increases as H-Al-MFI > H-Ga-MFI > H-BMFI. ${ }^{[24]}$ Notably, borosilicates exhibit $\sim 80-100$ $\mathrm{kJ} / \mathrm{mol}$ higher DPE values than aluminosilicates, making them weakly acidic. ${ }^{[24,25]}$ It is therefore unsurprising that purely borosilicate zeolites are rarely used for acid catalysis and have been traditionally used either as precursor to the synthesis of Lewis acid catalysts, ${ }^{[26,27,28]}$ or more recently to modify the textural or acidic properties of aluminosilicates. ${ }^{[29,30,31,32]}$ Among other examples, Chen et al. have reported that incorporation of the appropriate amount of boron concentrates the aluminum more selectively in the sinusoidal channels of MWW; ${ }^{[29]}$ others have been able to tune aluminum siting by competitive boron incorporation in other frameworks including MFI ${ }^{[32,33]}$ and BEA. ${ }^{[34]}$ Furthermore, Gounder and co-workers have recently shown that boron incorporation can be used to regulate crystallite sizes in MFI independent of total aluminum content. $^{[30]}$

We have recently highlighted the mechanisms and pathways for THF dehydra-decyclization on ZSM-5. ${ }^{[35]}$ These cyclic ethers undergo ratelimiting ring-opening on Brønsted acid sites to an alkoxide, which rearranges and dehydrates to form unsaturated alcohols as intermediates, followed by 


\section{Chem Rxiv ${ }^{\text {Th }}$}

their dehydration to form dienes. The key competing pathway is retro-Prins condensation, which results from the fragmentation of the adsorbed $\mathrm{C}_{\mathrm{n}}$ ether / alkoxide to $\mathrm{C}_{\mathrm{n}-1}$ olefin and formaldehyde. 2-MTHF is more reactive than THF and 3-MTHF towards $\mathrm{C}-\mathrm{O}$ bond rupture due to a kinetically relevant carbenium transition state ion pair formed upon ring opening, ${ }^{[36,37]}$ and is extensively studied for hydrodeoxygenation to pentanols, and consequently pentane, on metalphosphide catalysts. ${ }^{[38,39,40,41]}$ Due to its high reactivity, 2-MTHF can act as a surrogate cyclic ether to probe weakly acidic materials in more detail for dehydra-decyclization ${ }^{[37]}$.

In this study, we consider aluminum- and boron-containing zeolites in three frameworks (MWW, MFI, and BEA) to understand the role of heteroatom identity and confining environments in the dehydra-decyclization of 2-MTHF-to-1,3pentadiene. Using site-normalized apparent kinetic measurements, B-sites are shown to have higher selectivity to C5 dienes, albeit at significantly lower proton-normalized rates than aluminosilicates. Moreover, borosilicates are shown to have $c a$. 3-6 times more total turnovers than aluminosilicates under investigated reaction conditions $(\mathrm{T}=573 \mathrm{~K}$, $\mathrm{P}_{2-\mathrm{MTHF}}=25-26$ torr, initial 2-MTHF conversion in the range $21-26 \%$ ). The diene distribution remains far from equilibrium, and higher bed residence times predictably lead to increments in 1,3pentadiene (1,3-PD) formation rates, consistent with its favorable thermodynamic conformation compared to 1,4-pentadiene (1,4-PD). The diene distribution is also framework-dependent; 10-MR channels in MFI and MWW show higher preference to 1,3-PD over 1,4-PD than 12-MR channels in BEA. These findings are then utilized to achieve a stable $\sim 86 \% 1,3$-PD yield on boroncontaining MWW framework.

\subsection{Materials and Methods.}

2.1 Material synthesis and characterization. The following were purchased and used without any further treatment: 2-methyltetrahydrofuran (2MTHF, $\geq 98 \%$ with BHT as stabilizer, TCI Chemicals), pyridine (99.8\%, Sigma Aldrich), tertbutylamine ( $\geq 98 \%$, Sigma Aldrich), 1,4-pentadiene ( $\geq 98 \%$, TCI chemicals), 1,3-pentadiene (cis- and trans- mixture, $\geq 98 \%$, TCI Chemicals), 4-penten1-ol ( $\geq 99 \%$, Sigma Aldrich), 4-penten-2-ol ( $\geq 99 \%$, Sigma Aldrich), 3-penten-1-ol ( $\geq 95 \%, \quad$ Alfa
Chemistry), 2-penten-1-ol ( $\geq 95 \%$, trans-, Sigma Aldrich) 2,6-di-tert-butyl pyridine (DTBP, $\geq 97 \%$, Sigma Aldrich), silicon-dioxide (quartz chips, 4-20 mesh, Sigma Aldrich), tetrapropylammonium hydroxide solution (TPAOH, $40 \mathrm{wt} \%$ in water, Sigma Aldrich), $\mathrm{NaOH}$ (Macron Chemicals), fumed silica (Cab-o-sil M5, scintillation grade, Acros Organics), ammonium nitrate ( $\geq 98 \%$, Sigma Aldrich), boric acid ( $\geq 97 \%$, Macron Chemicals), anhydrous borax $\left(\mathrm{Na}_{2} \mathrm{~B}_{4} \mathrm{O}_{7}, \geq 99 \%\right.$, Sigma Aldrich), tetrapropylammonium hydroxide (TPAOH $40 \mathrm{wt} \%$ in water, Alfa Aesar), piperidine (99 \%, Sigma Aldrich), tetraethylammonium hydroxide solution (TEAOH, 40 wt \% in water, Sigma Aldrich), hexamethyleneimine ( $\geq 99 \%$, Sigma Aldrich), tetraethyl orthosilicate (TEOS, $\geq 99 \%$, Sigma Aldrich), cetyltrimethylammonium chloride (CTAB, Sigma-Aldrich, 99\% purity), sodium aluminate (MP Biomedicals).

The $\mathrm{NH}_{4}^{+}$form of ZSM-5 (CBV8014, $\mathrm{Si} / \mathrm{Al}=40$ ), and Al-BEA (CP814C, Si/Al=12.5) were purchased from Zeolyst International. MCM$22 \quad(\mathrm{Si} / \mathrm{Al}=24)$ was synthesized using hexamethyleneimine as the structure-directing agent using the same procedure reported by Corma and co-workers, ${ }^{[42]}$ (detailed procedure is included in Section S1.1 in the SI). MCM-36 was prepared by swelling and pillaring of MCM-22 as reported by Maheshwari et al. ${ }^{[43]}$ (detailed procedure is included in Section S1.1 in the SI). Boroncontaining zeolites in three different frameworks $\mathrm{MWW},{ }^{[26]} \mathrm{BEA},{ }^{[44,45]}$ and $\mathrm{MFI}^{[24]}$ were synthesized modifying existing hydrothermal synthesis procedures, and detailed steps are included in Section S1.1 in the SI. All catalysts were calcined in a boat placed within a 1" quartz tube under air flow at $823 \mathrm{~K}$ using a ramp rate of $2 \mathrm{~K} \mathrm{~min}^{-1}$ for 10 hours prior to any catalytic testing.

Powder X-ray diffraction (XRD) patterns were collected on a Bruker AXS D5005 diffractometer using $\mathrm{Cu} \mathrm{K}_{\alpha}$ radiation (=1.5418 $⿱$ $)$ with a step size of $0.02^{\circ}$ and a step time of four seconds. Inductively Coupled Plasma Optical Emission Spectrometry (ICP-OES) was used for elemental analysis. Textural information of all synthesized samples was characterized through $\mathrm{Ar}$ physisorption in an Autosorb iQ2 porosimetry instrument (Quantachrom). Prior to analysis, catalysts were outgassed at $573 \mathrm{~K}$ for six hours and subsequently cooled down to room temperature 
Table 1. Structural, textural, and acidic properties of all zeolites

\begin{tabular}{|c|c|c|c|c|c|c|c|}
\hline Catalyst & Provenance & $\mathbf{S i} / \mathbf{T}^{a}$ & $\begin{array}{c}\text { BET } \\
\text { Surface area } \\
\left(\boldsymbol{m}^{2} / \mathbf{g}\right)^{b}\end{array}$ & $\begin{array}{c}\text { Total pore } \\
\text { volume }\left(\mathrm{cm}^{3} / \mathrm{g}\right)^{c}\end{array}$ & $\begin{array}{c}\text { BAS } \\
(\mu \mathrm{mol} / \mathrm{g})\end{array}$ & $\boldsymbol{H}^{+} / \mathbf{T}$ & $\boldsymbol{R}_{S E M}(\mu \mathrm{m})^{g}$ \\
\hline MCM-22 & This work & 24.1 & 562 & 0.28 & 447.6 & $0.68^{d}$ & $1.8 \pm 0.6$ \\
\hline MCM-36 & This work & 32.3 & 645 & 0.41 & 233.8 & $0.47^{d}$ & $6.3 \pm 1.2$ \\
\hline B-MWW & This work & 13.2 & 506 & 0.30 & 149.6 & $0.13^{e}$ & $15.3 \pm 0.7$ \\
\hline ZSM-5 & Zeolyst & $40.0^{f}$ & 405 & 0.26 & 345.3 & $0.81^{d}$ & $0.44 \pm 0.09$ \\
\hline B-MFI & This work & 38.3 & 510 & 0.29 & 49.5 & $0.11^{e}$ & $0.32 \pm 0.11$ \\
\hline Al-BEA & Zeolyst & $12.5^{f}$ & 439 & 0.29 & 624.6 & $0.46^{d}$ & $0.58 \pm 0.12$ \\
\hline B-BEA & This work & 23.8 & 474 & 0.28 & 61.1 & $0.09^{e}$ & $3.7 \pm 0.4$ \\
\hline $\begin{array}{l}{ }^{\mathrm{a}}(\mathrm{T}=\mathrm{Al} / \mathrm{B}) \mathrm{De} \\
\text { from } \mathrm{Ar} \text { adso } \\
\text { elimination of } \\
\text { range 453-477 }\end{array}$ & mined by ICP-OE & (Galbra & Laboratories); & etermined from $\mathrm{Ar}$ ad & rption-desorp & $\begin{array}{l}\text { tion isothe } \\
\text { formed }\end{array}$ & $\begin{array}{l}\mathrm{ms} ;{ }^{c} \text { Determined } \\
\text { om the Hoffman } \\
\text { a the temperature } \\
\text { icrographs, with }\end{array}$ \\
\hline
\end{tabular}

under vacuum. BET specific surface area measurements were used to represent the total surface area of the catalyst materials; total pore volume was determined using a single point measurement at $\mathrm{P} / \mathrm{P}_{0}=0.95$. SEM was performed on a JEOL JSM-6500F scanning microscope operated at $2.0 \mathrm{kV}$. All TEM images were obtained with a FEI Tecnai G2 F30 TEM operating at 300 $\mathrm{kV}$ using a charge-coupled device (CCD) camera. MAS NMR experiments were performed using a Bruker DSX-500 and a Bruker 4.0 mm MAS probe. The spectral frequencies were 500.2, 160.5, and 99.4 MHz for ${ }^{1} \mathrm{H},{ }^{11} \mathrm{~B}$, and ${ }^{29} \mathrm{Si}$ nuclei, respectively. Samples were spun at $13 \mathrm{kHz}$ for ${ }^{1} \mathrm{H}$ and ${ }^{11} \mathrm{~B}$ detections, and $8 \mathrm{kHz}$ for ${ }^{29} \mathrm{Si}$. For ${ }^{11} \mathrm{~B}$ MAS NMR, $0.5 \mathrm{sec} \pi / 12$ pulse was used. The chemical shifts were calibrated to external references of TMS for ${ }^{1} \mathrm{H}$ and ${ }^{29} \mathrm{Si}$, and $\mathrm{BF}_{3}(\mathrm{OEt})_{2}$ for ${ }^{11} \mathrm{~B}$.

2.2 Catalytic Experiments. All kinetic measurements were performed in the temperature range of $430-550 \mathrm{~K}$ at total pressures of 1.00-1.05 bar in an upflow fixed bed reactor. Catalyst samples were pressed and sieved to particle sizes ranging from 250-500 $\mu \mathrm{m}$ and placed between deactivated quartz wool plugs in a $1 / 4$ " quartz U-tube. Void volume in the tube was minimized by loading quartz chips upstream of the catalyst bed. A 1/16" K-type thermocouple (Omega) was placed just above the reactor bed for temperature measurements. The furnace temperature was regulated by using a temperature PID controller (Omega CN 7800). All catalyst samples were calcined in situ at $823 \mathrm{~K}$ in $40 \mathrm{sccm}$ air $(99.997 \%$, Minneapolis Oxygen) using a ramp rate of $3.0 \mathrm{~K}$ $\mathrm{min}^{-1}$. The reactor was thereafter cooled to reaction temperature and purged with $\mathrm{He}$ (99.995\%, Matheson) for at least 30 minutes prior to introducing the reactant feed to eliminate temperature gradients across the bed. Reactant partial pressures were varied using a combination of carrier gas flowrates $(10-150 \mathrm{sccm})$ by a mass flow controller (Brooks Instruments 5850E), and volumetric flowrate of the reactant using a syringe pump (Cole Parmer 74905 series). All transfer lines were maintained at temperatures $\geq 400 \mathrm{~K}$ to avoid condensation of any species. Online analysis of the reactor effluent was performed using a gas chromatograph (Agilent 6890) equipped with a quantitative carbon detector (QCD, Polyarc $\left.{ }^{\mathrm{TM}}\right)^{[46]}$ and a flame ionization detector (FID). Separation was performed using an HP-PLOT Q column (Agilent, 19091P-QO4). All carbon mass balances closed to within $\pm 10 \%$. Unless otherwise specified, error bars represent $95 \%$ confidence intervals on independent replicate measurements on fresh catalyst beds from the same batch. As noted earlier, retro-Prins condensation of 2-MTHF produces butenes and formaldehyde in equimolar ratio, and 
the amount of formaldehyde was indirectly calculated by the quantification of butenes.

A combination of Mears' and Weisz-Prater criterion was used to investigate the external and internal mass transfer limitations, respectively (Section $\mathbf{S 2}$ in SI). ${ }^{[47]}$ Under near differential conditions $\left(\mathrm{X}_{2-\mathrm{MTHF}}<13 \%\right)$, while the rates for BEA and MFI (with both heteroatoms) were found to be free from any diffusional limitations, such a conclusion could not be reached for B-MWW and MCM-22, and the reported rates on these materials likely reflect a complex interplay of reaction and intra-crystalline diffusion. All aluminosilicates deactivated under reaction conditions over time scales of a few hours, and all reported rates were corrected to a bare catalyst surface by using a firstorder deactivation model and extrapolating obtained rates to time zero. Kinetic experiments at different temperatures were conducted using fresh catalyst beds to minimize systematic errors. Alternatively, borosilicates deactivated at much longer time scales than aluminosilicates, and reported rates on these materials were all corrected to a reference condition of $523 \mathrm{~K}$ to account for any small intervening deactivation during kinetic measurements. Brønsted acid site densities of all aluminosilicates were measured using the Hoffman-elimination of tert-butylamine. The Reactive Gas Chromatography (RGC) ${ }^{[48]}$ technique was used to quantify all butene isomers resulting from Hoffman elimination of tert-butylamine on a Brønsted acid site (BAS), assuming each butene molecule was produced on a unique BAS.

Previous works by Gorte and co-workers shows that alkylamines can desorb without undergoing Hoffman elimination on the acid sites in borosilicates due to their low reactivity. ${ }^{[49]}$ Moreover, the nature of these sites as well as boron coordination changes with the extent of hydration, ${ }^{[50]}$ and it is likely that part of tetrahedral boron in solid state ${ }^{11} \mathrm{~B}$ MAS NMR is actually trigonally coordinated under reaction conditions. To account for these factors, the BAS count for borosilicates was estimated by in situ pyridine titration experiments during 2-MTHF dehydradecyclization in the temperature range $453-477 \mathrm{~K}$. 2-MTHF dehydra-decyclization was carried out until initial transients subsided, and an instantaneous switch was made to the 2MTHF/pyridine mixture (molar ratio 310:1) at identical volumetric flowrate. Total 2-MTHF consumption rate was monitored with titrant uptake and linearly extrapolated to zero rates to quantify the total number of catalytically relevant acid sites in borosilicates. Experiments with selective DTBP titrations to deconvolute the catalytic role of different pore systems in aluminum-containing MWW (namely MCM-22, and MCM-36) were conducted at $453 \mathrm{~K}$, sufficiently lower than temperatures corresponding to the onset of DTBP desorption on aluminosilicates. ${ }^{[51,52]}$ Similar to in situ pyridine titration on borosilicates, 2-MTHF dehydra-decyclization was carried out for a fixed time (ca.175 minutes), and an instantaneous switch was made to 2-MTHF/DTBP mixture (molar ratio 650:1) at identical volumetric flowrate. Separation of compounds for these measurements were performed with a Restek RTx-5 column.

Experiments to evaluate the stability of all catalysts were performed at $573 \mathrm{~K}$ and $\mathrm{p}_{2-\mathrm{MTHF}} \sim 25$ torr; bed residence times and carrier gas flowrates were adjusted on different catalysts to achieve an initial conversion of $\sim 21-26 \%$. To provide a quantitative description of stability, we used total turnovers during catalyst lifetime (Eq. 3), which is a measure for the total moles of 2-MTHF converted to carbonaceous products per proton over the entire lifetime of catalyst. ${ }^{[53]}$ Total TONs were calculated until the conversions for all catalysts decreased to $\leq 3 \%$. The time scales to achieve this criterion for borosilicates was 300-470 h on stream, while aluminosilicates completely deactivated within 2475 hours. Furthermore, by calculating the fraction of total turnovers (Eq. 4), product selectivities (Eq. 2) were compared as a function of reaction progress allowing us to compare selectivities on catalysts with non-identical total turnovers.

$$
S T Y_{i}=\frac{F_{i}}{m_{\text {cat } . N_{H^{+}}}}
$$

$\frac{\text { Selectivit } y_{i}(\mathrm{C} \% \text { basis })}{100}=\frac{\text { Total carbon present in the product } i}{\text { Total carbon from the reactant converted to products }}$ (2) 


$$
\operatorname{TON}(t)=\frac{1}{N_{H^{+}}} \int_{0}^{t} \sum_{n} n . F_{C_{n}}\left(t^{\prime}\right) d t^{\prime}=\int_{0}^{t} \sum_{n} n . S T Y_{C_{n}}\left(t^{\prime}\right) d t^{\prime}
$$

$$
f_{\text {total-turovers }}(t)=\frac{\operatorname{TON}(t)}{\operatorname{TON}\left(t_{X_{2 M T H F} \leq 3 \%}\right)}
$$

where $F_{i}$ is the molar flow-rate of product $i, \mathrm{~N}_{H^{+}}$is the Brønsted acid site (BAS) density, $\mathrm{STY}_{i}$ is the site time yield for product $i, \mathrm{~m}_{\text {cat. }}$ is mass loading of the catalyst, and $n_{i}$ is the number of carbon atoms in product $i$.

\subsection{Results and Discussion.}

\subsection{Characterization of Synthesized} materials. Powder X-ray diffraction patterns, scanning and/or transmission electron microscopy images, and Ar-porosimetry measurements of MCM-22/MCM-36/B-MWW, ZSM-5/B-MFI, AlBEA/ B-BEA are reported in Figures S1, S2, and S3, respectively, of the SI (Section S1.2-1.4). A detailed discussion of the boron environments and the corresponding results of ${ }^{11} \mathrm{~B}$ and ${ }^{29} \mathrm{Si} \mathrm{MAS}$ NMR are included in the SI (Section S1.5 and Figure S4); these data were found consistent with previous reports on borosilicate zeolites with threeand four-coordinated boron (details in Section S1.5). Elemental analyses, textural properties, Brønsted acid site densities, and crystallite sizes of all catalysts are listed in Table 1.

Trace aluminum impurities in borosilicates have frequently lead to misinterpretation of their catalytic properties, ${ }^{[30]}$ and the catalytic rates with boroaluminosilicate materials have been shown to scale with aluminum contents as low as $\sim 100$ ppm. ${ }^{[54,55]}$ To avoid these artifacts in this work, high-purity silica source Cab-o-Sil M5 was used instead of Ludox colloidal silica for all borosilicate synthesis to eliminate the presence of aluminum, and ICP-OES (Galbraith laboratories) showed $\mathrm{Si} / \mathrm{Al} \geq 11,000$ in synthesized borosilicates, leading to $\leq 1.5 \mu \mathrm{mol} / \mathrm{g}$ BAS density from trace aluminum. As discussed later, the most active borosilicate (per mass basis) in this study (B-MWW) also has the highest boron content. Both of these results indicate that the synthesized borosilicates are sufficiently free from aluminum impurities.

The acid site density in borosilicates was measured using in-situ pyridine titration during 2MTHF dehydra-decyclization in the temperature range $453-477 \mathrm{~K}$. The mole fraction of pyridine was kept low $\left(\sim 1.9 \times 10^{-5}\right)$ so the partial pressure of 2 MTHF before and after its introduction could be assumed the same. The reduction in massnormalized total 2-MTHF conversion rates were monitored with the uptake of the titrant, and the total number of B-sites were calculated by the cumulative pyridine uptake to completely suppress the rates (Figure 1). While the titration for BMWW was carried out at $453 \mathrm{~K}$, the corresponding experiments for B-MFI and B-BEA were carried out at $473 \mathrm{~K}$ and $477 \mathrm{~K}$, respectively, due to their significantly lower reactivity than B-MWW (also discussed in Section 3.2).

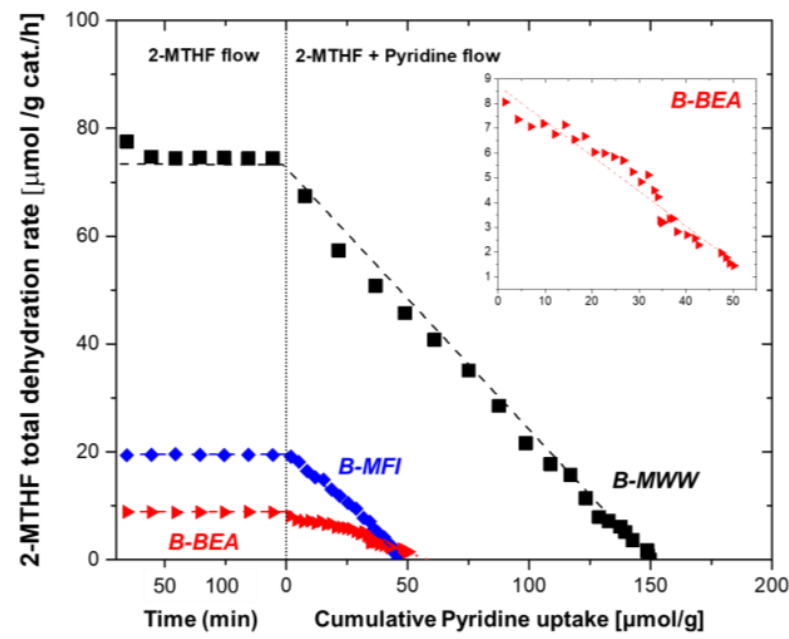

Figure 1. Total consumption rate of 2-MTHF as a function of pyridine uptake over B-MWW( $\mathbf{n})$, B-MFI $(\diamond), \mathrm{B}-\mathrm{BEA}(\boldsymbol{)})$; Inset shows the corresponding data for B-BEA on a magnified scale. Titrant flow is an equivalent volumetric flowrate of 2-MTHF/Pyridine with 2- MTHF: Pyridine 310. Inset shows the data for B-BEA on a magnified scale. (Reaction conditions: $\mathrm{T}=$ $453 \mathrm{~K}$ for B-MWW, $473 \mathrm{~K}$ for B-MFI, and $477 \mathrm{~K}$ for B$\mathrm{BEA} ; \mathrm{p}_{2 \mathrm{MTHF}}=10.5$ torr for B-MWW, 4.5 torr for B$\mathrm{BEA}$ and B-MFI; WHSV $=0.60-4.50 \mathrm{~g}$ 2-MTHF/g cat./h; Carrier gas (He) flowrate $=60 \mathrm{sccm}$ for B-MWW, $40 \mathrm{sccm}$ for B-MFI and B-BEA; $\mathrm{X}_{2 \mathrm{MTHF}} \leq 1 \%$ ).

Pyridine was found to titrate all the B-sites relevant in 2-MTHF dehydra-decyclization on BMWW, as shown by the complete suppression of rates (Figure 1). For B-BEA and B-MFI, the rates 
dropped to $\sim 85-90 \%$ of their initial values. Furthermore, upon switching back the feed to 2MTHF after pyridine saturation, we did not observe the recovery of rates even at $477 \mathrm{~K}$ for over two hours, which indicates that pyridine remains a reversible yet strongly bound titrant for B-sites initially titrated in the temperature range investigated. The irreversible nature of pyridine adsorption has previously been shown at slightly lower temperature $(433 \mathrm{~K})$ during methanol dehydration on B-MFI. ${ }^{[24]}$ The results (Figure 1) confirm the presence of acid sites which can protonate pyridine in these materials, the quantification of which allows for the calculation of site time yields (STYs) for the dehydradecyclization pathway. Notably, the number of protons per heteroatom for boron-containing zeolites remains significantly lower than corresponding values for aluminosilicates (Table 1), as has been reported by Jones et al. previously for B-MFI. ${ }^{[24]}$ Unlike aluminosilicates, the site homogeneity indicated by framework-independent

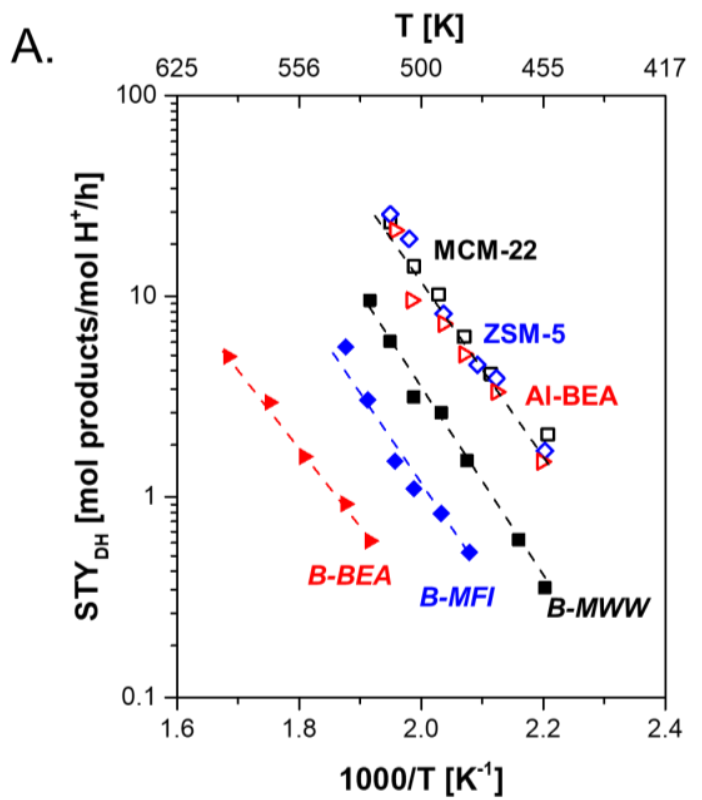

DPE values has not been established for borosilicates, and it is possible that a majority of boron in the borosilicates is either not associated with a proton, or a fraction of protons associated with B lack the acidic strength to protonate pyridine irreversibly under the reaction conditions. However, it is reasonable to assume that the fraction of $\mathrm{B}$ sites unable to protonate pyridine (proton affinity $=930 \mathrm{~kJ} / \mathrm{mol})^{[56]}$ cannot protonate 2-MTHF (proton affinity $=851 \mathrm{~kJ} / \mathrm{mol}$ ) either. ${ }^{[57]}$ Therefore, the reported STYs on these materials are likely accurate even if this method does not titrate all acid sites in borosilicates.

As shown in Figure 1, the mass-normalized 2MTHF consumption rates for B-MFI were almost twice the corresponding value for B-BEA, even though total boron content in B-BEA was $\sim 1.5 \mathrm{x}$ higher than B-MFI. Moreover, B-MFI and B-BEA had similar total BAS counts ( $\sim 50$ and $\sim 60 \mu \mathrm{mol} / \mathrm{g}$, respectively) (Table 1). Thus, the dehydradecyclization site time yields for B-MFI were $2.4 \mathrm{x}$ higher than B-BEA, even at $5 \mathrm{~K}$ lower

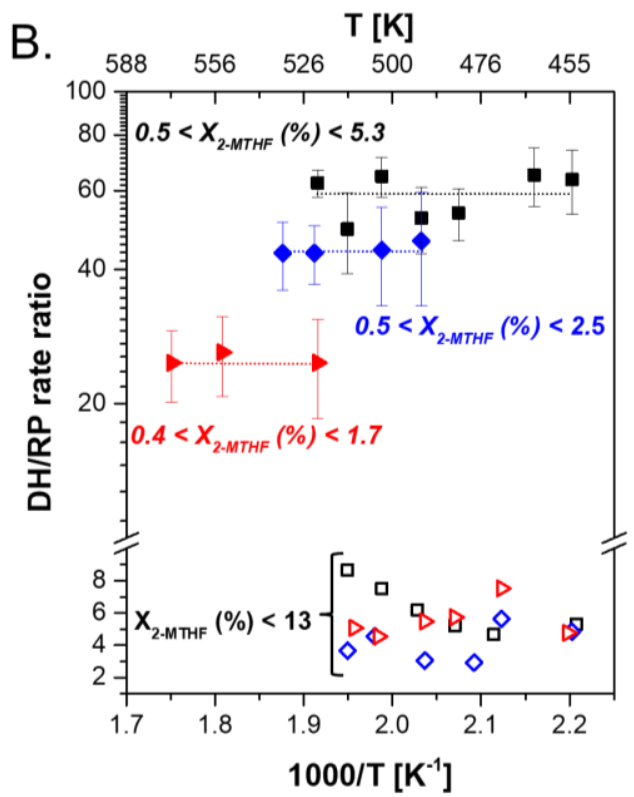

Figure 2. (A) Arrhenius plots of apparent kinetics for the dehydra-decyclization of 2-MTHF and b) tem- perature dependence of dehydra-decyclization (DH) to Retro-Prins condensation (RP) rate ratios over B-MWW( $\mathbf{\square}), \mathrm{MCM}-22$ $(\square)$, B-MFI $(\diamond)$, ZSM5 $(\diamond)$, B-BEA $(\triangleright)$, and Al-BEA $(\triangleright) ; X_{2 M T H F}$ denotes the conversion of 2-MTHF. (Reaction conditions: $\mathrm{p}_{2 \mathrm{MTHF}}=10.5$ torr, Space velocity $=1.10-10.35 \mathrm{molec}$. $2-\mathrm{MTHF} / \mathrm{H}^{+} / \mathrm{min}$, Carrier gas $(\mathrm{He})$ flowrate of 60 $\mathrm{ml} / \mathrm{min}, \mathrm{X}_{2 \mathrm{MTHF}} \leq 13 \%$ ). Dashed lines in (a) are fits to Arrhenius equation, and dashed lines in (B) are to guide the eye. Brønsted acid site counts $\left(\mathrm{mol} \mathrm{H}^{+}\right)$for aluminosilicates and borosilicates are quantified using the Hoffman elimination of tert-butylamine, and in-situ pyridine titrations during 2-MTHF dehydra-decyclization, respectively. Error bars in b) are standard errors originating from uncertainty in the estimation of Retro-Prins condensation (RP) rates for borosilicates due to their low activity coupled with low selectivity to this pathway. 
Table 2. Measured apparent kinetic parameters of 2-MTHF dehydra-decyclization on different zeolites.

\begin{tabular}{ccccc}
\hline & $\begin{array}{c}\mathbf{E}_{a p p, D H} \\
(\mathbf{k c a l} / \mathbf{m o l})^{a}\end{array}$ & $\boldsymbol{S T Y}_{\boldsymbol{D H}}\left(\times \mathbf{1 0}^{-3} \boldsymbol{s}^{-\mathbf{1}}\right)$ & $\boldsymbol{S T Y}_{\boldsymbol{R} \boldsymbol{P}}\left(\times \mathbf{1 0}^{-3} \boldsymbol{s}^{-\mathbf{1}}\right)$ & $\mathbf{D H} / \mathbf{R P} \mathbf{~ r a t i o}$ \\
\hline ZSM-5 & $21.5 \pm 1.5$ & $7.11^{b}$ & $1.94^{b}$ & 3.7 \\
Al-BEA & $19.9 \pm 1.4$ & $5.92^{b}$ & $1.17^{b}$ & 5.1 \\
MCM-22 & - & $6.50^{b}$ & $0.75^{b}$ & 8.7 \\
B-MWW & - & $1.65^{b}$ & $0.038^{b}$ & $49.2 \pm 10.1$ \\
B-MFI & $22.5 \pm 2.3$ & $0.42^{b}$ & $0.013^{b}$ & $31.9 \pm 12.6$ \\
B-BEA & $18.2 \pm 0.8$ & $0.17^{c}$ & $0.007^{c}$ & $24.61 \pm 6.4$ \\
\hline
\end{tabular}

${ }^{a}$ Determined by apparent kinetic measurements under conditions described in Figure 2, where the errors are 95\% CI on the slope. The STYs on MWW materials were not under strict kinetic control under reaction conditions (Section S2 in the SI), and therefore $\mathrm{E}_{a p p, D H}$ is not reported on these materials; ${ }^{b}$ Reported at $\mathrm{T}=512 \mathrm{~K} ;{ }^{c}$ Reported at $\mathrm{T}=522 \mathrm{~K}$. Errors in the calculations of Retro-Prins condensation STYs for borosilicates are reflected in the standard errors of the corresponding $\mathrm{DH} / \mathrm{RP}$ rate ratios.

temperature. Since the rates do not scale linearly with bulk boron content, these results indicate that the relative distribution of active boron species is different in the three borosilicates investigated. Furthermore, these results underpin the necessity to probe the acidity of borosilicates strictly under reaction conditions due to their complex speciation behavior and changes in coordination upon contacting basic molecules including oxygenates.

An accurate explanation for this frameworkdependent catalytic behavior of borosilicates would involve the estimation of Brønsted acid site strength of boron sites in these three frameworks. However, the different possible boron environments (Figure S4 in the SI) as well as the presence of crystallographically distinct T-sites which may differ in their DPE values, makes the estimation of a single representative DPE value difficult without also having a priori knowledge of relative distributions of these sites under reaction conditions. The distinct behavior of boron sites in SOD and FER frameworks has been highlighted before by Fois et al., who probed these sites by first principles calculations to study the non-identical nature of ammonia adsorption on these materials. $^{[58]}$

3.2 Effect of heteroatom identify in dehydradecyclization selectivity. The application of borosilicates and boron-modified aluminosilicates to selectively suppress the production of side reactions has been previously implemented for several chemistries. Some examples where boronmodified zeolites were utilized for this purpose include: dehydration of 2,3-butanediol to butanone over boric acid impregnated on ZSM-5; ${ }^{[59]}$ Beckmann rearrangement of cyclohexanone oxime to caprolactam on B-MFI, ${ }^{[60,61]}$ and B-ZSM-5; ${ }^{[62]}$ catalytic cracking of MTBE to isobutene and methanol on B-MFI; ${ }^{[63]}$ intramolecular Prinscyclisation of citronellal on B-TUD- $1 ;^{[64]}$ isomerization of 1-hexene on B-MCM-41, ${ }^{[65]}$ dehydrative aromatization of 2,5-dimethylfuran (DMF) to p-xylene on B-BEA, ${ }^{[25]}$ and dehydration of 2-methylbutanal to isoprene. ${ }^{[66]}$

The known reaction pathways during the conversion of 2-MTHF over Brønsted acid sites are shown in Scheme 1. Consistent with this scheme, major products observed in our reactor effluent included 1,3- and 1,4-pentadiene (dehydradecyclization products), butenes and formaldehyde (retro-Prins condensation products), propene, pentenes, and large organics (identified as aromatic $\mathrm{C}_{6+}$ fraction). We conducted apparent kinetic rate measurements in the temperature range $453-573 \mathrm{~K}$ to assess the relative rates and selectivities to dehydra-decyclization and retro-Prins condensation, and the results are shown in Fig. 2.

The dehydra-decyclization rates were found invariant across the three frameworks in aluminosilicates (Table 2), indicating that 


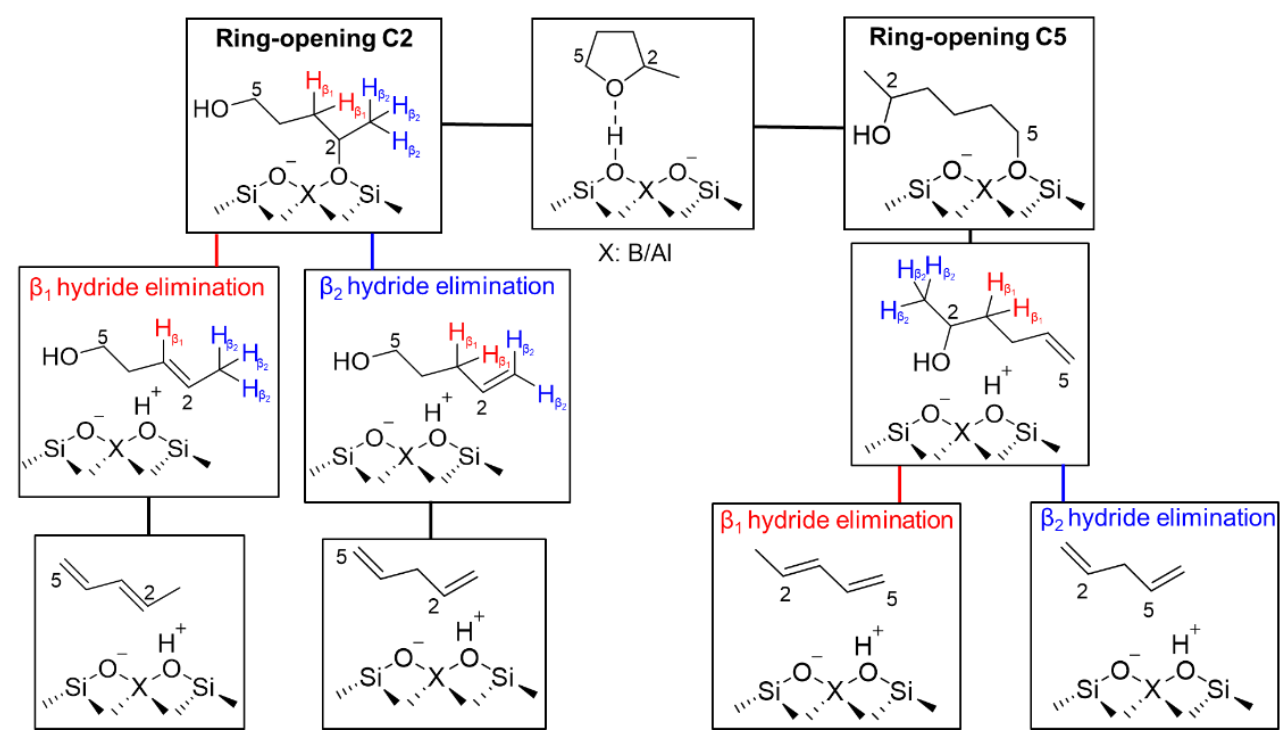

Scheme 2. Proposed pathways for the production of 1,3-Pentadiene and 1,4-Pentadiene from 2-MTHF over Brønsted acid sites.

kinetically relevant ring-opening transition-state (TS) ion-pair ${ }^{[35]}$ is likely stabilized to the same extent in MWW, MFI and BEA. Consequently, the apparent activation energies for the dehydradecyclization pathway on aluminosilicates (BEA, and MFI) are $\sim 20 \mathrm{kcal} / \mathrm{mol}$ (Table 2). These results are consistent with Kumbhalkar et al., who have also reported identical proton-normalized site-time yields for pentadienes' production over aluminosilicates having different micropore environments and extra-framework aluminum (ZSM-5 ( $\mathrm{Si} / \mathrm{Al}=11.5), \mathrm{Al}$-BEA $(\mathrm{Si} / \mathrm{Al}=12.5)$, and Al-MOR $(\mathrm{Si} / \mathrm{Al}=10)){ }^{[37]}$ The apparent dehydradecyclization barrier of $17.7 \mathrm{kcal} / \mathrm{mol}$ on amorphous $\mathrm{Si} / \mathrm{Al}$ in the temperature range 570-660 $\mathrm{K}$ is also qualitatively close to the values obtained by us, and small differences are likely caused by changes in apparent kinetics resulting from the differences in surface coverages at high temperature conditions employed in their study. Notably, these activation barriers are $\sim 10-12$ $\mathrm{kcal} / \mathrm{mol}$ lower than four-carbon THF-dehydradecyclization on ZSM-5 reported in our earlier work under similar reaction conditions, ${ }^{[35]}$ providing further corroboration of the promotingeffect of a methyl substituent on the stabilization of the kinetically relevant transition state.

Borosilicates catalyze the dehydradecyclization pathway at STYs which are at least $\sim 5 \mathrm{x}$ lower than aluminosilicates (Figure 2a). Furthermore, they exhibit different dehydradecyclization STYs depending on framework type unlike aluminosilicates. Remarkably, there is approximately an order-of-magnitude difference in the dehydra-decyclization STY between the most active (B-MWW) and least active (B-BEA) borosilicate at given temperature $(523 \mathrm{~K})$. These results indicate that the speciation behavior of active sites in these materials is catalytically different depending on $B$ siting and/or the micropore environments around the B-site. Furthermore, the nature of apparent kinetics for the dehydra-decyclization pathway remains similar on borosilicates as indicated by similar apparent barriers as on aluminosilicates (Table 2).

The suppression of the retro-Prins (RP) condensation pathway on borosilicates is much greater $(\sim 30-50 x)$ than the suppression of dehydradecyclization (DH) pathway, leading to higher diene selectivities (Figure $\mathbf{2 b}$ and Table 2). Consequently, these materials show $\sim 6 \mathrm{x}-30 \mathrm{x}$ higher $\mathrm{DH} / \mathrm{RP}$ rate ratios than aluminosilicates under near-differential conditions $\left(\mathrm{X}_{2-\mathrm{MTHF}}<13 \%\right)$ (Figure 2b). This likely results from the inability of weakly acidic B-sites to fragment a C-C bond (the rate-determining step for retro-Prins condensation $^{[35]}$ ). Furthermore, this behavior is not 2-MTHF conversion-dependent, and borosilicates 
show $\sim 90 \%$ selectivity to dienes across all conversions, which is ca. $10-30 \%$ higher than aluminosilicates under similar reaction conditions (Table S2 in SI). These results, taken together, provide experimental evidence that weakly acidic borosilicates limit the kinetic branching to competing retro-Prins pathway in this chemistry.

3.3 Distribution of diene products. Besides the production of butenes and formaldehyde in the competing retro-Prins reaction pathway, another challenge to selectively produce the conjugated 1,3pentadiene (1,3-PD) is the concurrent production of the non-conjugated 1,4-pentadiene (1,4-PD) during 2-MTHF dehydra-decyclization. This is illustrated in Scheme 2; 2-MTHF can ring-open from the more substituted ' $\mathrm{C}-2$ side' or the less substituted ' $\mathrm{C}-5$ side'. Ring opening from the ' $\mathrm{C}-2$ side' is likely more favorable, given the carbenium character of the kinetically relevant transition state associated with ether ring opening, and leads to the formation of primary alkenols, namely, 3-penten-1-ol (E2 type elimination of $\mathrm{H}_{\beta 1}$ ) or 4-penten-1-ol (E2 type elimination of $\mathrm{H}_{\beta 2}$ ). While the dehydration of 3penten-1-ol leads to 1,3-pentadiene, 4-penten-1-ol dehydration leads to 1,4-pentadiene. Alternatively, the alkoxide formed upon ring-opening from the ' $\mathrm{C}-5$ ' side can only form a secondary alkenol, namely, 4-penten-2-ol. This alkenol can further undergo dehydration to form 1,3-pentadiene (E2 type elimination of $\mathrm{H}_{\beta 1}$ ) or 1,4-pentadiene (E2 type elimination of $\mathrm{H}_{\beta 2}$ ).

To assess the validity of Scheme 2, we conducted experiments by feeding pure C5 alkenols, namely, 4-penten-1-ol, 3-penten-1-ol, 4penten-2-ol, and 2-penten-1-ol, over ZSM-5 at lower temperature $(413 \mathrm{~K})$ than 2-MTHF reaction temperatures, primarily to maintain differential conditions given the facile dehydration of these alkenols. It was found that the preference to produce 1,3-pentadiene from different alkenols follows 2-penten-1-ol >> 4-penten-2-ol > 3-penten1-ol 4-penten-1-ol (Figure S9 in the SI).

Neither 3-penten-1-ol nor 4-penten-1-ol were purely selective to 1,3-pentadiene and 1,4pentadiene, respectively. Moreover, the most active and selective intermediate to 1,3-pentadiene, namely 2-penten-1-ol, does not result directly from a simple E2 elimination of the adsorbed alkoxides indicated in Scheme 2. Previous reports have highlighted that the migration of a double bond on a carbon chain is a low barrier step, ${ }^{[67,68]}$ and consistent with this, these results indicate that both the intermediate primary alkenols as well as the produced dienes can inter-convert on a Brønsted acid site, which limits mechanistic interpretations about the origin of diene distribution directly from 2-MTHF.

3.3.1 Tuning selectivity to 1,3 -pentadiene. 1,3-Pentadiene is thermodynamically more stable than 1,4-PD. ${ }^{[37,69]}$ Using gas-phase thermochemistry data from NIST, it was found that all diene distributions were far from equilibrium under the reaction conditions in this study; selectivity to 1,3-PD was not equilibrium-limited (Section S.4 in SI). 1,3-PD was formed as a favored diene with both borosilicates and aluminosilicates, and there was no obvious correlation between the 1,3-PD/1,4-PD selectivity ratio and heteroatom identity in the range of space times investigated (Figure 3), which is not surprising given this ratio would not only depend on the reactivity of protons, but also on their volume density, as well as the corresponding crystallite sizes. However, the preference towards 1,3-PD increased with reactor space times on all investigated zeolites irrespective of the heteroatom identity. For aluminosilicates, the total diene production rates were higher at low space times, and the increase in 1,3-PD production was only partly as a result of secondary enhancements due to 1,4-PD isomerization. However, on borosilicates, the increments in 1,3PD formation rates was concommitant with the decrease in 1,4-PD production such that the overall diene selectivity remained nearly unchanged in the space times investigated $\left(0.01-10 \mathrm{H}^{+}\right.$. $\mathrm{min} / \mathrm{molec}$. 2MTHF). These results, taken together, indicate that the diene ratio can be tuned towards the conjugated 1,3-PD by operating under reaction conditions which facilitate the isomerization of the nonconjugated 1,4-PD. They also imply that the spatial gradients in diene concentrations are observable on the length scales of reactor bed lengths, and a fraction of 1,4-pentadiene formed at small bed 
length desorbs and reacts further down in the bed to form the thermodynamically favored 1,3-PD.

One would expect the more reactive protons in aluminosilicates to be more consequential in depleting unfavorable 1,4-pentadiene concentrations, and it was expected that the 1,3$\mathrm{PD} / 1,4-\mathrm{PD}$ rate ratio would depend more sensitively on space time (or, equivalently, show higher slopes w.r.t. space time) on aluminosilicates than borosilicates. Interestingly, this was not found to be the case (Figure 3). While aluminosilicates are known to catalyze double bond isomerizations, ${ }^{[70,71,72]}$ this observation suggested that even the weakly acidic borosilicates can isomerize 1,4-PD to 1,3-PD. This hypothesis was tested by feeding pure 1,4-pentadiene and 1,3pentadiene over borosilicates, and the results are shown in Figure S8. 1,3-pentadiene did not show any conversion to 1,4-pentadiene on all borosilicates, consistent with its significantly higher thermodynamic preference than 1,4-PD. Furthermore, the preference towards 1,3pentadiene on borosilicates (B-MWW > B-MFI > B-BEA) (Figure 3) was directly correlated with their reactivity for 1,4-pentadiene isomerization (Figure S8), confirming that the isomerization of 1,4-pentadiene remains facile, even on the weakly acidic borosilicates.

Interestingly, 12-MR BEA with both heteroatoms ( $\mathrm{B}$ and $\mathrm{Al}$ ) consistently exhibited a lower 1,3-PD/1,4-PD ratio than MWW and MFI frameworks across two decades of space times (Figure 3). Furthermore, the preference to 1,3-PD was more pronounced when these measurements were not in the strict kinetic regime $\left(\mathrm{X}_{2 \mathrm{MTHF}}=30\right.$ $60 \%$ in Figure 3). These observations led to our hypothesis that differences in 1,3-PD production are likely through different extents of diffusionenhanced isomerization of 1,4-PD rather than differenes in diene kinetic preference between the investigated frameworks. For example, 10-MR channels in MFI likely impose more severe transport restrictions faciliataing 1,4-PD isomerization than 12-MR channels in BEA, leading to higher 1,3-PD production rates in MFI. However, such direct interpretations could not be drawn for MWW materials due to the highly non-

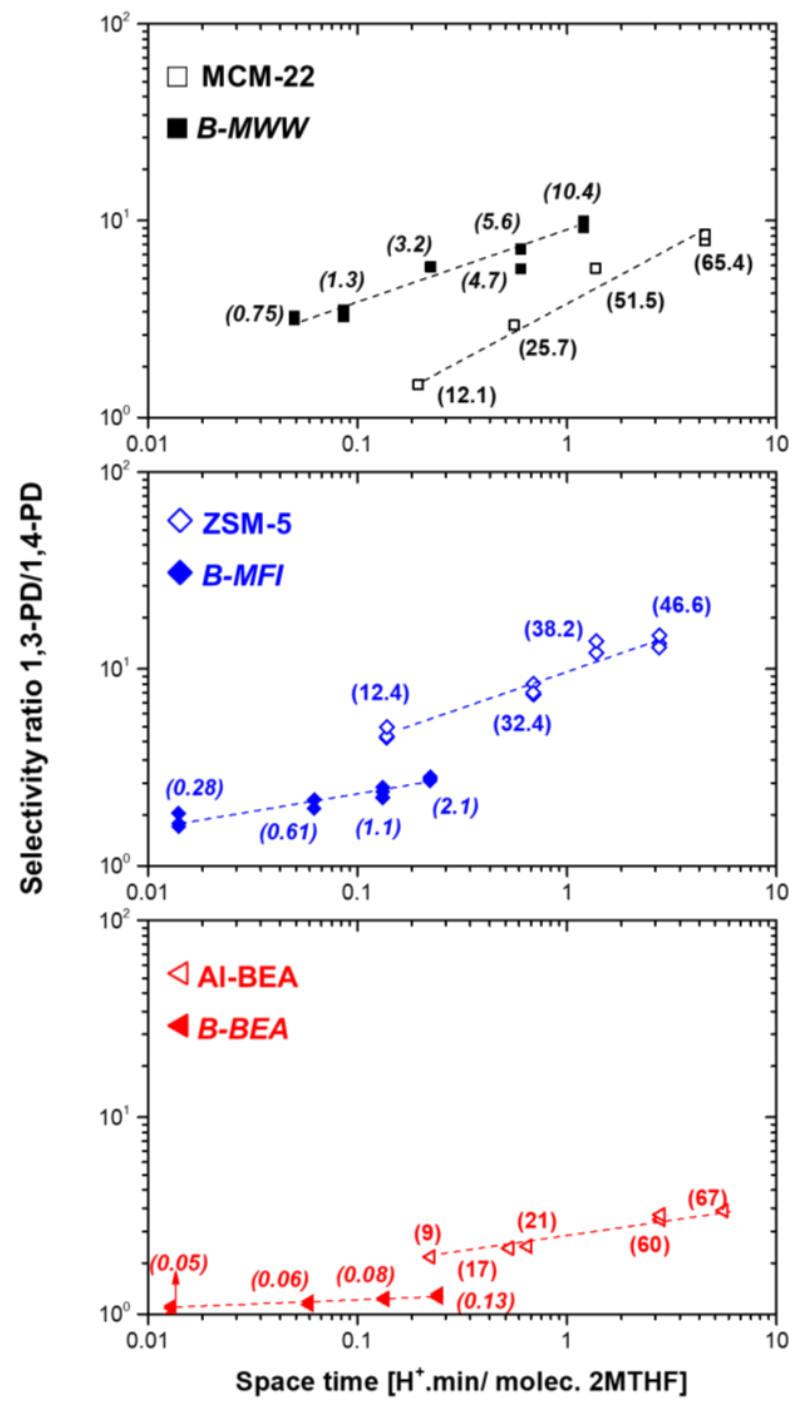

Figure 3. Measured selectivity ratios of 1,3Pentadiene/1,4-Pentadiene as a function of reactor space-times over B-MWW(-), MCM-22 (), B-MFI $(\diamond)$, ZSM-5 $(\diamond)$, B-BEA $(\triangleleft)$, and Al-BEA $(\triangleleft)$ (Reaction conditions: $\mathrm{T}=503 \mathrm{~K}, \mathrm{p}_{2-\mathrm{MTHF}}=1.5-120$ torr, Carrier gas (He) flowrate of $60 \mathrm{ml} / \mathrm{min}$ ). The bracketed values are the corresponding conversion levels. Dashed lines are provided to guide the eye.

distinct pore systems in its topology (discussed in Section 3.3.2). Deconvoluting the catalytic role of these distinct pore systems would therefore provide insights into the origin of diene distribution on solid acids. To test our hypothesis, we designed (DTBP) titration experiments on alumniumn-containing MWW materials to study the change in diene distributioin as the chemistry was restricted 


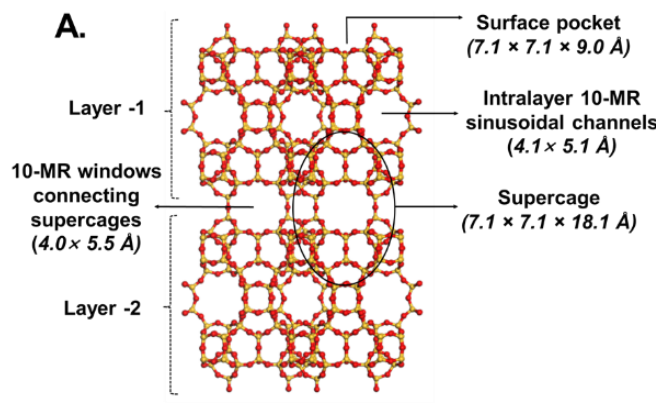

B.

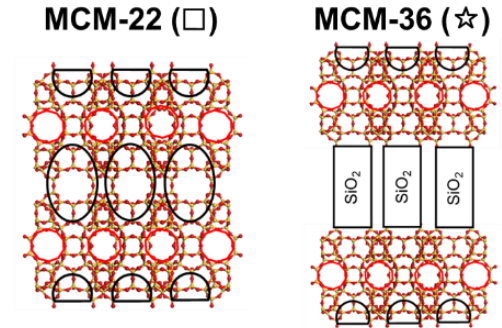

Supercages and surface side-pockets Intra-layer 10-MR sinusoidal channels
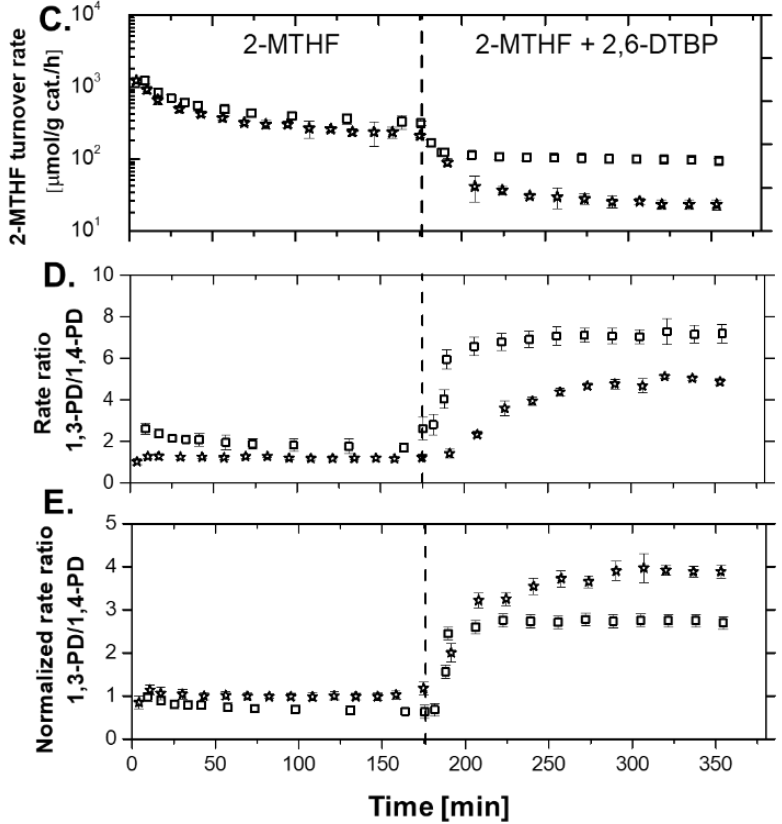

Figure 4. (A) Detailed schematic of MWW framework indicating the location and relative sizes of all pore systems; (B) Detailed schematic of MCM-22 and MCM-36 framework topology; (C) Total rate of consumption of 2-MTHF; (D) Absolute values of 1,3-PD/1,4-PD rate ratio; and (E) Normalized rate ratio of 1,3-PD/1,4-PD (normalized to t=0) as a function of time-on-stream after the introduction of DTBP titrant for MCM-22 (口), and MCM-36 (汭). Titrant flow is an equivalent volumetric flowrate of 2-MTHF/DTBP with 2-MTHF: DTBP 650:1 (Reaction conditions: T $=453 \mathrm{~K}, \mathrm{p}_{2 \mathrm{MTHF}}=10.5$ torr, $\mathrm{WHSV}=3.97-5.05 \mathrm{~g} 2-\mathrm{MTHF} / \mathrm{g}$ cat $\left./ \mathrm{h}, \mathrm{X}_{2 \mathrm{MTHF}} \leq 8 \%\right)$.

selectively to a pore system smaller than in MFI (intra-layer 10-MR sinusoidal channels).

3.3.2 Deconvoluting the pore systems of aluminum-containing MWW in catalysis. MWW is formed by calcination of a precursor layered material and consists of two independent pore systems (Figure 4a). The intra-layer pore network consists of two-dimensional sinusoidal 10MR channels $(4.1 \times 5.1 \AA)$. Perpendicular to these sinusoidal channels are larger supercages $(7.1 \times$ $7.1 \times 18.1 \AA$ ) interconnected by elliptical $10-\mathrm{MR}$ windows $(4.0 \times 5.5 \AA)$. The transport between the two pore systems is restricted by 6-MR constrictions. The external surface of MWW crystals is terminated by supercages, which leads to the formation of hourglass shaped surface sidepockets $(7.1 \times 7.1 \times 9.0 \AA)$. The MWW precursor can be swelled and pillared prior to calcination to preserve the intra-layer crystallinity. ${ }^{[43,73]}$ Given our previous results indicate the higher preference of 1,3-PD in medium-pore MFI than large-pore BEA, the presence of two different pore systems makes MWW a suitable topology to probe the effects of micropore environments in the production of 1,3pentadiene.

Many recent reports have demonstrated the different catalytic performance of acid sites located in these distinct confining environments in MWW for various chemistries like methanol-tohydrocarbons (MTH), ${ }^{[29,74]}$ toluene disproportionation, ${ }^{[75]}$ and methylcyclohexane ${ }^{[76]} /$ n-heptane cracking. ${ }^{[77]}$ While the sites in the side pockets are on the external surface and can be titrated with bulky bases that do not interact with intra-layer sinusoidal channels, the method cannot be used for titrating acid sites in the supercages due to their inter-connectivity through ellipsoidal 10MR channels. On the other hand, smaller bases like pyridine have been shown to titrate all sites in MWW. ${ }^{[78]}$ However, on swelling and pillaring the MWW precursor, the supercages don't collapse to form a 3-D structure after calcination, and this procedure leads to the preservation of long-range intra-layer crystallinity while creating inter-layer mesoporosity (Figure 4b). Upon successsful pillaring, a bulky base like DTBP can titrate not 
only the external surface side-pocket sites, but also the sites in the supercages which are now hourglass shaped surface side-pockets located in a mesoporous environment. This allows probing the catalytic role of different pore systems in determining the diene distribution by sequentailly restricting the chemistry to happen in the internal acid sites by DTBP tiration on MCM-22, and subsequently only in the 10-MR intra-layer sinusoidal channels by DTBP titration on MCM-36.

Prior reports have estimated that MCM-22 has $\sim 8 \%$ sites in the external side-pockets, which can be titrated using DTBP during probe reactions like ethanol dehydration. ${ }^{[78,79]}$ However, we observed a significantly higher $(\sim 38 \%)$ decrease in 2-MTHF consumption rates on MCM-22 upon DTBP saturation (Table 3 and Figure 4c). It has been shown that DTBP can access pore-mouth and channel-intersection sites in $\mathrm{MWW},{ }^{[79]}$ and it is reasonable to expect that the accessibility of DTBP to these sites imposes more severe transport restrictions on 2-MTHF than ethanol, rendering some untitrated acid sites inaccessible to 2-MTHF. Besides, the ratio of external to internal sites in MWW depends on the particle size, and a higher drop in rates could also reflect more external specific surface area viz-à-viz previous reports. Both the decrease in the rates (Table 3 and Figure 4c) and the time scales over which the rate dropped, were higher on MCM-36 than MCM-22, clearly indicating a higher number of sites being accessible to DTBP in MCM-36.

Table 3. Comparison of 2-MTHF dehydra-decyclization STYs before and after saturation by 2,6- DTBP as titrant on MCM-22, and MCM-36.

\begin{tabular}{|c|c|c|}
\hline & $\begin{array}{l}\text { STY }_{\text {DH }} \\
\left(\mathbf{h}^{-1}\right)\end{array}$ & $\begin{array}{c}\text { Rate loss after DTBP } \\
\text { saturation (\%) }\end{array}$ \\
\hline MCM-22 & $2.9 \pm 0.2$ & 37. \\
\hline MCM-36 & $5.3 \pm 0.4$ & $84.7 \pm 2.1$ \\
\hline \multicolumn{3}{|c|}{$\begin{array}{l}\text { Reaction conditions: } \mathrm{T}=453 \mathrm{~K}, \mathrm{p}_{2 \mathrm{MTHF}}=10.5 \text { torr, } \mathrm{X}_{2 \mathrm{MTHF}}<8 \% \\
\text { Space velocities in the range of } 0.37-1.25 \mathrm{molec} .2-\mathrm{MTHF} / \mathrm{H}^{+} / \mathrm{min} \text {; } \\
\text { cate loss was calculated using the equation: } 1-(\text { residual rate after DTB } \\
\text { saturation/Rate immediately prior to titrant introduction }) \times 100(\%) \text {. A } \\
\text { error bars represent a } 95 \% \text { CI from three independent measurement } \\
\text { on fresh/recalcined beds. }\end{array}$} \\
\hline
\end{tabular}

As seen in Figure 4d, the selectivity ratio of 1,3-PD/1,4-PD was in the range of $\sim 2-3$ prior to DTBP introduction on MCM-22, while it was $~ 1.0-$
1.2 for MCM-36, illustrating the role of pore environments on the diene distribution; mesopore environments in MCM-36 were detrimental to 1,3PD production, consistent with our other findings. Upon the introduction of DTBP, the diene distribution shifted towards the conjugated diene on both catalysts. To study the relative changes in the diene distribution independent of absolute values, the formation rate ratio of 1,3-PD/1,4-PD was normalized by its initial value (at time zero). This also ensured that any product distribution changes due to catalyst deactivation did not affect the mechanistic interpretations. Concomitant with DTBP saturation, the normalized 1,3-/1,4-PD rate ratio on MCM-22 increased with the uptake of DTBP and stabilized at $\sim 2.8$ (Figure 4e). As noted earlier, this diene distribution still has contribution of intra-layer sinusoidal channels and supercages. Nonetheless, this result indicates that the diene distribution shifts towards 1,3-PD when the catalytic contribution of external acid sites is completely suppressed. Most notably, the normalized 1,3-/1,4-PD rate ratio increased significantly upon DTBP introduction on MCM-36, and stabilized at $\sim 4$. As noted earlier, the sites in the super-cages are made accessible through pillaring of MCM-22. Hence, any residual rate after DTBP saturation on MCM-36 can be directly attributed to the intra-layer 10-MR sinusoidal channels. Indeed, when the chemistry was restricted to occur only in these sinusoidal channels, the diene distribution became highly skewed in favor of the conjugated 1,3-pentadiene. Once again, we note that these measurements were not performed in strictly kinetic regime (Section S2. in SI), thus supporting our other findings that impediment in diffusion facilitates 1,4-PD isomerization, thus leading to increments in 1,3-PD selectivity in medium-pore (10-MR) zeolitic channels.

3.4 Long-term stability of borosilicates. Catalytic evaluation of borosilicates or boronmodified aluminosilicates has been shown to increase time-on-stream stability for a variety of chemistries. ${ }^{[31,32,59,80,81,82]}$ However, recent reports have highlighted the limitations of using time-onstream (TOS) as a metric of catalyst stability, specially when comparing materials with varying 

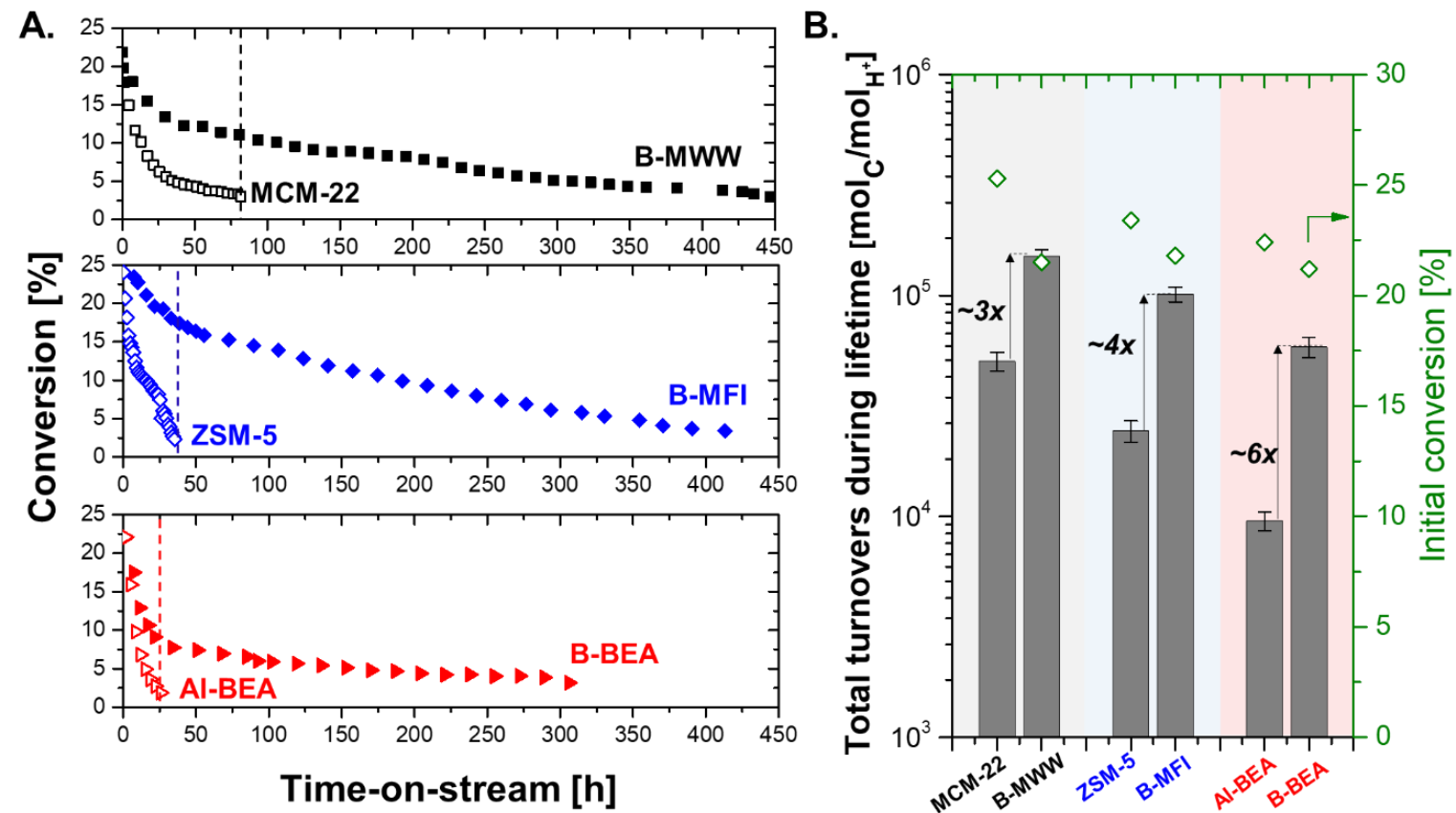

Figure 5. (A) 2-MTHF conversion as a function of time-on-stream on B-MWW(-), MCM-22 (口), B-MFI (४), ZSM$5(\diamond)$, B-BEA $(\triangleright)$, and Al-BEA $(\triangleright)$; (B) Total turnover numbers during catalyst lifetime (primary axis), and initial conversion (secondary axis) for all zeolites. (Reaction conditions: $\mathrm{T}=573 \mathrm{~K}, \mathrm{p}_{2 \mathrm{MTHF}}=25-26$ torr, Space velocity $=$ 7.22-24.3 molec. 2-MTHF/H $/ \mathrm{H}^{+} \mathrm{min}$, Carrier gas $(\mathrm{He})$ flowrate $\left.=10-140 \mathrm{ml} / \mathrm{min}\right)$. Error bars represent the standard errors in the calculation of total turnovers with the trapezoidal rule.

reactivity, ${ }^{[33,83,84]}$ as is the case with the two classes of zeolites in this study. We therefore use total turnover numbers per reactive proton (TON) during catalyst lifetime as the stability criteria (Eq. 3). ${ }^{[53]}$ As noted earlier, turnover number at time-onstream $t$ is the cumulative moles of 2-MTHFderived carbon converted to all products per mole of active site from time-on-stream 0 to time, $t$. The reactivity differences between boro-, and aluminosilicates manifest themselves in the different site-time yields (STYs) in (Eq. 3). This formalism further allows us to study changes in selectivity trends as a fraction of total turnovers, which is a more rigorous selectivity comparison for catalysts disparate in total TONs. ${ }^{[53]}$

Figure 5a shows the conversions on all zeolites as a function of time-on-stream (TOS). In all the three investigated frameworks, borosilicates exhibited $\sim 8-13 \mathrm{x}$ lifetimes, indicating their significantly higher stability under reaction conditions. Interestingly, for both alumino-, and borosilicates, the catalyst lifetime decreased in the order MWW > MFI > BEA. It is likely that C-C chain elongation steps terminate at shorter chain lengths in the 10-MR frameworks MFI and MWW. However, these condensation reactions leading to coking precursors occur more readily in the straight 12-MR channels of BEA and are detrimental to total catalyst lifetime. Figure $\mathbf{5} \mathbf{b}$ shows the total TONs for all zeolites employed in this study. As expected from the time-on-stream data, borosilicates showed $\sim 3-6 \mathrm{x}$ higher total TONs than aluminosilicates starting from similar 2-MTHF conversions (Figure 5 b).

The product selectivities of all major products under reaction conditions were plotted as a function of total turnovers (Eq. 4) and are shown in Figure 6. As the catalysts deactivated, the selectivity to both 1,3-pentadiene and 1,4-pentadiene decreased for all zeolites; this reduction was mirrored by an increase in $\mathrm{C} 6+$ products (identified as alkylated aromatics), which are likely the coking precursors. Based on this observation, we conclude that linear pentadienes can further undergo condensation and/or cyclization reactions leading to these larger fractions. The product selectivity towards butenes was consistently lower on borosilicates than aluminosilicates at all stages of reaction progress, 

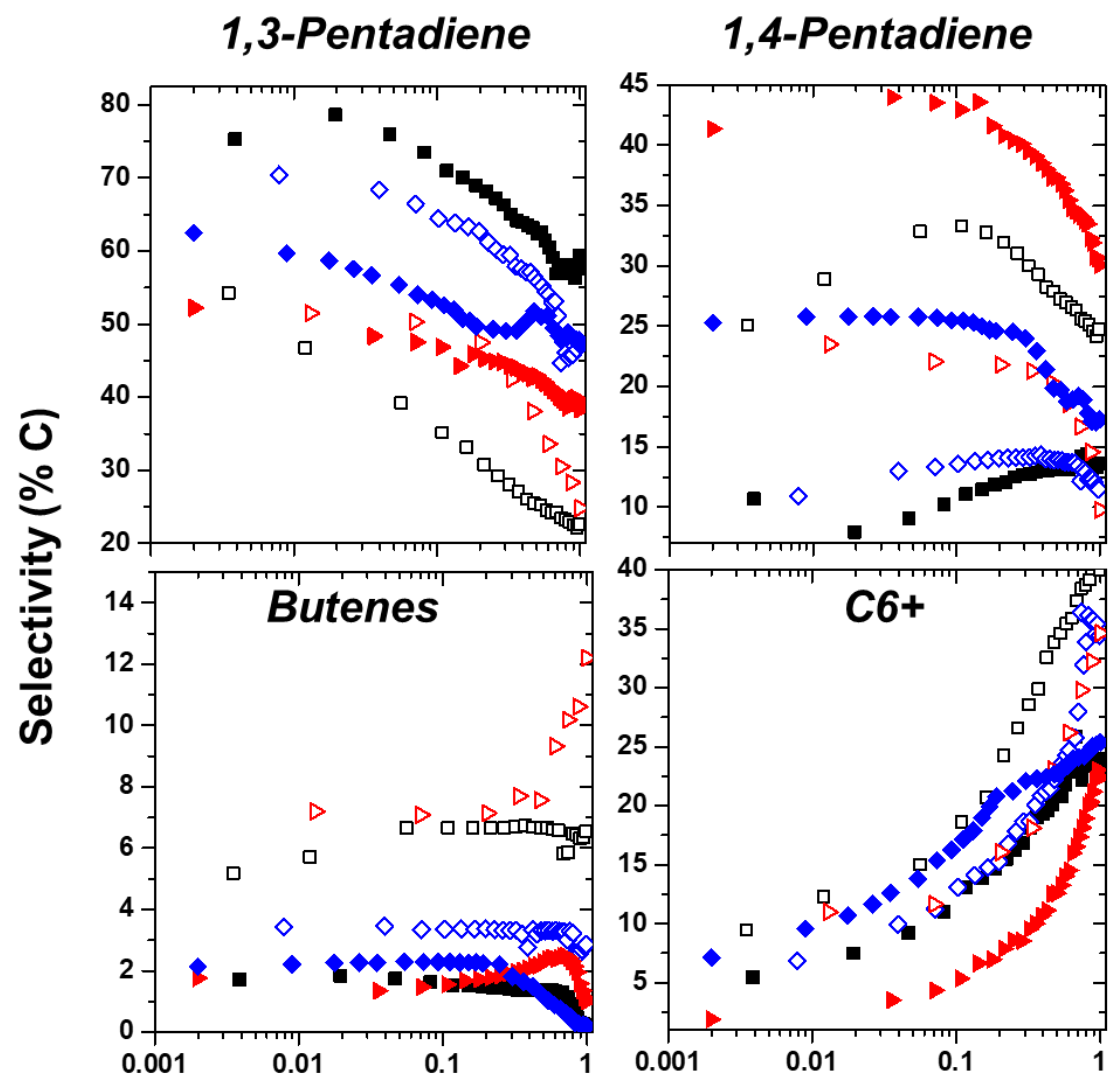

Fraction of total turnovers

Figure 6. Selectivity to (left to right and top to bottom) 1,3-Pentadiene, 1,4-Pentadiene, butenes, and C6+ compounds,

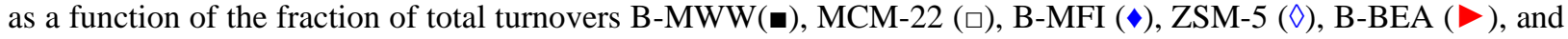
Al-BEA $(\triangleright)$; Reaction conditions are same as Figure 5.

consistent with the inability of borosilicates to fragment C-C bonds. Notably, the selectivity to higher $\mathrm{C} 6+$ fraction was consistently lower in borosilicates $(\sim 15-22 \%)$ than aluminosilicates $(25-$ $40 \%$ ), especially later in the reaction progress $\left(f_{\text {total-turovers }}(t)>0.5\right)$, when the catalysts had significantly deactivated. This is likely a result of weak binding of these larger hydrocarbons, enabling desorption from boron-acid sites but irreversible adsorption and consequent condensation reactions on the aluminum acid sites, leading to coke formation. It is therefore likely that the higher stability of borosilicates is a direct consequence of reduced $\mathrm{C} 6+$ fraction formation.

3.5 Maximizing the yield of 1,3-pentadiene in the dehydra-decyclization chemistry. Recent reports of renewable catalytic pathways to piperylene production have utilized 2-MTHF as a feedstock. Other feeds have been less common, but a notable recent example includes a two-step deoxydehydration of xylitol leading to a 1,3pentadiene yield of $\sim 52 \%$. ${ }^{[85]}$ The hydrogenolysis of 2-MTHF is a frequently studied chemistry on metal phosphides, but the presence of high pressure of $\mathrm{H}_{2}$ leads to the production of saturated species, and the overall yield to pentadienes is typically low; Oyama and co-workers have reported $\sim 50 \%$ yield of pentadienes during the hydrodeoxygenation of 2MTHF over $\mathrm{WP} / \mathrm{SiO}_{2}$ at $548 \mathrm{~K}{ }^{[39]}$ Other reports have reported negligible production of pentadienes in this chemistry. ${ }^{[38,40,41]}$

Dehydra-decyclization of 2-MTHF appears to be a promising chemistry to obtain high yields of 1,3-PD; Norman has recently reported that a ternary $\mathrm{V}$-Ti-P oxide results in $\sim 59 \%$ 1,3-PD yield during 2-MTHF dehydra-decyclization. ${ }^{[86]}$ Dumesic and co-workers have reported $68 \%$ combined $1,3+1,4-$ pentadiene yield in the same chemistry on 
amorphous silica/alumina. ${ }^{[33]}$ However, their reported yield dropped from $68 \%$ to $52 \%$ over 58 hours on-stream due to catalyst deactivation. Our previous studies on phosphorus-containing zeosils, while selective to dienes at low conversions, show a moderate yield of dienes of $60 \%$ at quantitative 2MTHF conversions. ${ }^{[12]}$

As noted before, borosilicates suppress both the competing retro-Prins pathway, as well as condensation reactions leading to $\mathrm{C} 6+$ fraction. Furthermore, these catalysts are significantly more stable under reaction conditions than aluminosilicates. Therefore, experiments were designed to probe borosilicates at near complete conversions to maximize the yield of dehydradecyclization products in this chemistry, which predictably required high temperature and low space velocity conditions due to their instrinsic low reactivity. The obtained overall diene selectivities on borosilicates were consistently in the range of 86-92\% independent of experimental conditions and conversion levels. Most notably, under these low space velocity $(0.85 \mathrm{~g} 2-\mathrm{MTHF} / \mathrm{g}$ cat./h) and high temperature $(658 \mathrm{~K})$ conditions, a total diene yield of $\sim 89 \%$ was observed on the borosilicate BMWW. More importantly, the yield of conjugated 1,3-pentadiene was found to be $\sim 86 \%$ (Figure S6), and the corresponding diene selectivities were sustained for over 80 hours on-stream. Due to the lower activity of B-MFI and B-BEA, the yields obtained were limited by 2-MTHF conversions, and under similar experimental conditions, the 1,3-PD yield was found to be $\sim 76 \%$ and $\sim 24 \%$ on B-MFI, and B-BEA, respectively.

4.0 Conclusions. The systematic catalytic evaluation of boro-, and aluminosilicates in three zeolite topologies (MWW, MFI, and BEA) reveals that weakly acidic borosilicates suppress the competing retro-Prins pathway to butenes, as well as complex condensation pathways leading to coking precursors in the dehydra-decyclization of 2-methyltetrahydrofuran, thus leading to $\sim 90 \%$ selectivity to dienes across different 2-MTHF conversions. The thermodynamic favorability of 1,3-pentadiene is shown by the increments in the diene distribution ratio of 1,3-/1,4-pentadiene by increasing reactor space-times and tighter micropore environments in MFI and MWW. Lastly, total catalyst lifetime in the chemistry is topologydependent, with 12-MR BEA showing lower TONs for both heteroatoms than MFI and MWW. Borosilicates exhibit a remarkable improvement in total catalyst lifetime in all three frameworks, ranging from $\sim 3 \mathrm{x}$ in MWW to $\sim 6 \mathrm{x}$ in BEA. These strategies are utilized to report a stable 1,3pentadiene yield of $\sim 86 \%$ on B-MWW.

Acknowledgements. This research was supported by the Center for Sustainable Polymers at the University of Minnesota, a National Science Foundation supported center for Chemical Innovation (CHE-1413862). Additional support was provided by the Minnesota Corn Growers Association. Parts of this work were carried out in the Characterization Facility, University of Minnesota, which receives partial support from NSF through the MRSEC program. We thank Dr. Sojong Hwang (Solid state NMR facility, Caltech) for all solid state NMR experiments, and Dr. Omar Abdelrahman, Dr. Anargyros Chatzidmitriou, and Dr. M. Alexander Ardagh for helpful technical discussions.

Keywords. Dehydra-decyclization, Retro-Prins Condensation, 1,3-pentadiene, 1,4-pentadiene

Supporting Information. Additional information is located in the online supporting information. 


\section{References}

${ }^{1}$ Sarkar, P.; Bhowmick, A. K. J. Appl. Polym. Sci. 2017, 45701, 45701.

${ }^{2}$ Mark Hillmyer. Science. 2016, 358 (6365), 868-870.

${ }^{3}$ Bruijnincx, P. C. A.; Weckhuysen, B. M. Angew. Chemie - Int. Ed. 2013, 52 (46), 11980-11987.

${ }^{4}$ Schneiderman, D. K.; Hillmyer, M. A. Macromolecules 2017, 50 (10), 3733-3749.

${ }^{5}$ Cespi. D; Passarini F; Vassura I; Cavani F. Green Chem. 2016, 18 (6), 1625-1638.

${ }^{6}$ Rabnawaz, M.; Wyman, I.; Auras, R.; Cheng, S. Green Chem. 2017, 19 (20), 4737-4753.

${ }^{7}$ Behr, A.; Neubert, P. ChemCatChem 2014, 6 (2), 412-428.

${ }^{8}$ Neubert, P.; Fuchs, S.; Behr, A. Green Chem. 2015, 17 (7), 4045-4052.

${ }^{9}$ Neubert, P.; Steffen, M.; Behr, A. J. Mol. Catal. A Chem. 2015, 407, 122-127.

${ }^{10}$ Neubert, P.; Meier, I.; Gaide, T.; Kuhlmann, R.; Behr, A. Catal. Commun. 2016, 77, 70-74.

${ }^{11}$ Abdelrahman, O. A.; Park, D. S.; Vinter, K. P.; Spanjers, C. S.; Ren, L.; Cho, H. J.; Zhang, K.; Fan, W.; Tsapatsis, M.; Dauenhauer, P. J. ACS Catal. 2017, 7 (2), 1428-1431.

${ }^{12}$ Abdelrahman, O. A.; Park, D. S.; Vinter, K. P.; Spanjers, C. S.; Ren, L.; Cho, H. J.; Vlachos, D. G.; Fan, W.; Tsapatsis, M.; Dauenhauer, P. J. ACS Sustain. Chem. Eng. 2017, 5 (5), 3732-3736.

${ }^{13}$ Kakiuchi, Y.; Tanigawa, T.; Tsunoji, N.; Takamitsu, Y.; Sadakane, M.; Sano, T. Appl. Catal. A Gen. 2019, 575, 204-213.

${ }^{14}$ Cho, H. J.; Ren, L.; Vattipalli, V.; Yeh, Y. H.; Gould, N.; Xu, B.; Gorte, R. J.; Lobo, R.; Dauenhauer, P. J.; Tsapatsis, M.; Fan, W. ChemCatChem 2017, 9 (3), 398-402.

${ }^{15}$ Wang, C.; Li, S.; Mao, X.; Caratzoulas, S.; Gorte, R. J. Catal. Letters 2018, 148 (11), 3548-3556.

${ }^{16}$ Lok, B. M.; Messina, C. A.; Patton, R. L.; Gajek, R. T.; Cannan, T. R.; Flanigen, E. M. J. Am. Chem. Soc. 1984, 106 (20), 6092-6093.

${ }^{17}$ Dai, W.; Wang, X.; Wu, G.; Guan, N.; Hunger, M.; Li, L. ACS Catal. 2011, 1 (4), 292-299.

${ }^{18}$ Martens, J. A.; Grobet, P. J.; Jacobs, P. A. J. Catal. 1990, 126 (1), 299-305.

${ }^{19}$ Chu C.T.W; Kuehl G.H.; Lago R.M; Chang C.D. J. Catal. 1985, 93, 451-458.

${ }^{20}$ Parrillo, D. J.; Lee, C.; Gorte, R. J.; White, D.; Farneth, W. E. J. Phys. Chem. 1995, 99 (21), 87458749.

${ }^{21}$ Agarwal, V.; Metiu, H. J. Phys. Chem. C 2015, 119 (28), 16106-16114.

${ }^{22}$ Yuan, S. P.; Wang, J. G.; Li, Y. W.; Jiao, H. J. Phys. Chem. A 2002, 106 (35), 8167-8172.
${ }^{23}$ Jones, A. J.; Iglesia, E. ACS Catal. 2015, 5 (10), 5741-5755.

${ }^{24}$ Jones, A. J.; Carr, R. T.; Zones, S. I.; Iglesia, E. J. Catal. 2014, 312, 58-68.

${ }^{25}$ Patet, R. E.; Koehle, M.; Lobo, R. F.; Caratzoulas, S.; Vlachos, D. G. J. Phys. Chem. C 2017.

${ }^{26}$ Ren, L.; Guo, Q.; Orazov, M.; Xu, D.; Politi, D.; Kumar, P.; Alhassan, S. M.; Mkhoyan, K. A.; Sidiras, D.; Davis, M.E.; Tsapatsis, M. ChemCatChem 2016, 8(7) 1274-1278.

${ }^{27}$ Dapsens, P. Y.; Mondelli, C.; Pérez-Ramírez, J. Chem. Soc. Rev. 2015, 44 (20), 7025-7043.

${ }^{28}$ Ouyang, X.; Hwang, S. J.; Runnebaum, R. C.; Xie, D.; Wanglee, Y. J.; Rea, T.; Zones, S. I.; Katz, A. J. Am. Chem. Soc. 2014, 136 (4), 1449-1461.

${ }^{29}$ Chen, J.; Liang, T.; Li, J.; Wang, S.; Qin, Z.; Wang, P.; Huang, L.; Fan, W.; Wang, J. ACS Catal. 2016, 6 (4), 2299-2313.

${ }^{30}$ Kester, P. M.; Miller, T.; Gounder, R. I\&EC 2018, 57(19), 6673-6683.

${ }^{31}$ Zhu, Q.; Kondo, J. N.; Yokoi, T.; Setoyama, T.; Yamaguchi, M.; Takewaki, T.; Domen, K.; Tatsumi, T. Phys. Chem. Chem. Phys. 2011, 13 (32), 1459814605.

${ }^{32}$ Li, C.; Vidal-Moya, A.; Miguel, P. J.; Dedecek, J.; Boronat, M.; Corma, A. ACS Catal. 2018, 8 (8), 7688-7697.

${ }^{33}$ Zhu, Q.; Kondo, J. N.; Setoyama, T.; Yamaguchi, M.; Domen, K.; Tatsumi, T. Chem. Commun. 2008, No. 41, 5164-5166.

${ }^{34}$ Korányi, T. I.; Nagy, J. B. J. Phys. Chem. B 2006, 110 (30), 14728-14735.

${ }^{35}$ Li, S.; Abdelrahman, O. A.; Kumar, G.; Tsapatsis, M.; Vlachos, D. G.; Caratzoulas, S.; Dauenhauer, P. J. ACS Catal. 2019, 9 (11), 10279-10293.

${ }^{36}$ Chia, M.; Pagán-Torres, Y. J.; Hibbitts, D.; Tan, Q.; Pham, H. N.; Datye, A. K.; Neurock, M.; Davis, R. J.; Dumesic, J. A. J. Am. Chem. Soc. 2011, 133 (32), 12675-12689.

${ }^{37}$ Kumbhalkar, M. D.; Buchanan, J. S.; Huber, G. W.; Dumesic, J. A. ACS Cat. 2017, 7(8), 5248-5256.

${ }^{38}$ Bui, P.; Takagaki, A.; Kikuchi, R.; Oyama, S. T. ACS Catal. 2016, 6 (11), 7701-7709.

${ }^{39}$ Bui, P.; Cecilia, J. A.; Oyama, S. T.; Takagaki, A.; Infantes-Molina, A.; Zhao, H.; Li, D.; RodríguezCastellón, E.; Jiménez López, A. J. Catal. 2012, 294, 184-198.

${ }^{40}$ Cho, A.; Kim, H.; Iino, A.; Takagaki, A.; Ted Oyama, S. J. Catal. 2014, 318, 151-161.

${ }^{41}$ Witzke, M. E.; Almithn, A.; Coonrod, C. L.; Hibbitts, D. D.; Flaherty, D. W. ACS Catal. 2018, 8 (8), 71417157. 
${ }^{42}$ Corma, A.; Pérez-Pariente C.C.; Zeolites, 1995, 15(1) 2-8.

${ }^{43}$ Maheshwari, S.; Jordan, E.; Kumar, S.; Bates, F. S.; Penn, R. L.; Shantz, D. F.; Tsapatsis, M. J. Am. Chem. Soc. 2008, 130 (4), 1507-1516.

${ }^{44}$ Koller, H.; Senapati, S.; Ren, J.; Uesbeck, T.; Siozios, V.; Hunger, M.; Lobo, R. F., J. Phys. Chem. C 2016, 120(18), 9811-9820.

45 Tong, H. T. T.; Koller, H. Microporous Mesoporous Mater. 2012, 148 (1), 80-87.

${ }^{46}$ Maduskar, S.; Teixeira, A. R.; Paulsen, A. D.; Krumm, C.; Mountziaris; Fan, W.; Dauenhauer, P. J.; Mountziaris, T. J.; Fan, W.; Dauenhauer, P. J. Lab Chip 2015, 15 (2), 440-447.

${ }^{47}$ H.S. Fogler, Elements of Chemical Reaction Engineering, Pearson Education Inc, Upper Saddle River, NJ, 2006.

${ }^{48}$ Abdelrahman, O.; Vinter, K. P.; Ren, L.; Xu, D.; Gorte, R. J.; Tsapatsis, M.; Dauenhauer, P. J. Catal. Sci. Technol. 2017, 7, 3831-3841.

${ }^{49}$ Kofke, T. J. G.; Gorte, R. J.; Kokotailo, G. T. J. Catal. 1989, 116 (1), 252-262.

${ }^{50}$ Hwang, S. J.; Chen, C. Y.; Zones, S. I. J. Phys. Chem. B 2004, 108 (48), 18535-18546.

${ }^{51}$ Góra-Marek, K.; Tarach, K.; Choi, M. J. Phys. Chem. C 2014, 118 (23), 12266-12274.

52 A. Corma L. Forni, F. Márquez, J. MartínezTriguero, D. Moscotti, V. F.; Mart, J.; Corma, A.; Forn, V.; Forni, L.; M, F. J. Catal. 1998, 179, 451458.

${ }^{53}$ Hwang, A.; Bhan, A. ACS Catal. 2017, 7 (7), 44174422.

${ }^{54}$ Chu, C. T. W.; Kuehl, G. H.; Lago, R. M.; Chang, C. D. J. Catal. 1985, 93 (2), 451-458.

${ }^{55}$ Yuen, L. T.; Zones, S. I.; Harris, T. V.; Gallegos, E. J.; Auroux, A. Microporous Mater. 1994, 2 (2), 105117.

${ }^{56}$ Hunter, E. P. L.; Lias, S. G. J. Phys. Chem. Ref. Data 1998, 27 (3), 413-656.

${ }^{57}$ Lias, S. G.; Liebman, J. F.; Levin, R. D. J. Phys. Chem. Ref. Data 1984, 13 (3), 695-808.

${ }^{58}$ Fois, E.; Gamba, A.; Tabacchi, G.; Trudu, F. First principles studies on boron sites; Zeolites and Related Materials: Trends, Targets and Challenges

Proceedings of 4th International FEZA Conference, Elsevier B.V., 2008; Vol. 174.

${ }^{59}$ Zhang, W.-G.; Yu, D.-H.; Ji, X.-J.; Huang, H. Green Chem. 2012, 14, 3441-3450.

${ }^{60}$ Röseler, J.; Heitmann, G.; Hölderich, W. F. Appl. Catal. A Gen. 1996, 144 (1-2), 319-333.

${ }^{61}$ Forni, L.; Fornasari, G.; Trifirò, F.; Aloise, A.; Katovic, A.; Giordano, G.; Nagy, J. B. Microporous Mesoporous Mater. 2007, 101, 161-168.
${ }^{62}$ Heitmann, G. P.; Dahlhoff, G.; Niederer, J. P. M.; Hölderich, W. F. J. Catal. 2000, 194 (1), 122-129.

${ }^{63}$ Nau A; Zanthoff H.W; Geilen F; Maschmeyer D; Winterberg, M; Peitz S; Bukohl R; Boeing C; US Patent 2015/0258535 A1, 2015.

${ }^{64}$ Ranoux, A.; Djanashvili, K.; Arends, I. W. C. E.; Hanefeld, U. RSC Adv. 2013, 3 (44), 21524.

${ }^{65}$ Sundaramurthy, V.; Eswaramoorthi, I.; Lingappan, N. Can. J. Chem. 2004, 82 (5), 631-640.

${ }^{66}$ Hoelderich W; Merger, F.; Mross W.F; Fouquet G; US Patent 4560822 1985, 1-4.

${ }^{67}$ Kondo, J. N.; Shao, L.; Wakabayashi, F.; Domen, K. J. Phys. Chem. B 1997, 101 (45), 9314-9320.

${ }^{68}$ Boronat, M.; Viruela, P.; Corma, A. J. Phys. Chem. A 1998, 102 (6), 982-989.

${ }^{69} \mathrm{Yu}, \mathrm{L}$.; Karton, A. Chem. Phys. 2014, 441, 166-177.

${ }^{70}$ Noh, G.; Zones, S. I.; Iglesia, E. J. Phys. Chem. C 2018, 122, 25475-25497.

${ }^{71}$ Noh, G.; Shi, Z.; Zones, S. I.; Iglesia, E. J. Catal. 2018, 368, 389-410.

${ }^{72}$ Sarazen, M. L.; Doskocil, E.; Iglesia, E. ACS Catal. 2016, 6 (10), 7059-7070.

${ }^{73}$ Tsapatsis, M.; Maheshwari, S. Angew. Chemie - Int. Ed. 2008, 47 (23), 4262-4263.

${ }^{74}$ Wang, S.; Wei, Z.; Chen, Y.; Qin, Z.; Ma, H.; Dong, M.; Fan, W.; Wang, J. ACS Catal. 2015, 5 (2), 11311144.

${ }^{75}$ Laforge, S.; Martin, D.; Guisnet, M. Appl. Catal. A Gen. 2004, 268 (1-2), 33-41.

${ }^{76}$ Matias, P.; Lopes, J. M.; Laforge, S.; Magnoux, P.; Russo, P. A.; Ribeiro Carrott, M. M. L.; Guisnet, M.; Ramôa Ribeiro, F. J. Catal. 2008, 259 (2), 190-202.

${ }^{77}$ Matias, P.; Lopes, J. M.; Laforge, S.; Magnoux, P.; Guisnet, M.; Ramôa Ribeiro, F. Appl. Catal. A Gen. 2008, 351 (2), 174-183.

${ }^{78}$ Liu, D.; Bhan, A.; Tsapatsis, M.; Al Hashimi, S. ACS Catal. 2011, 1 (1), 7-17.

${ }^{79} \mathrm{Wu}$, Y.; Emdadi, L.; Qin, D.; Zhang, J.; Liu, D. Microporous Mesoporous Mater. 2017, 241, 43-51.

${ }^{80}$ Qiao, Q.; Wang, R.; Gou, M.; Yang, X. Microporous Mesoporous Mater. 2014, 195, 250-257.

${ }^{81} \mathrm{Hu}, \mathrm{Z}$; Z Zhang, H.; Wang, L.; Zhang, H.; Zhang, Y.; Xu, H.; Shen, W.; Tang, Y. Catal. Sci. Technol. 2014, 4 (9), 2891-2895.

${ }^{82}$ Yang, Y.; Sun, C.; Du, J.; Yue, Y.; Hua, W.; Zhang, C.; Shen, W.; Xu, H. Catal. Commun. 2012, 24, 4447.

${ }^{83}$ Hwang, A.; Kumar, M.; Rimer, J. D.; Bhan, A. J. Catal. 2017, 346, 154-160.

${ }^{84}$ Bligaard, T.; Bullock, R. M.; Campbell, C. T.; Chen, J. G.; Gates, B. C.; Gorte, R. J.; Jones, C. W.; Jones, W. D.; Kitchin, J. R.; Scott, S. L. ACS Catal. 2016, 6 (4), 2590-2602. 
${ }^{85}$ Sun, R.; Zheng, M.; Li, X.; Pang, J.; Wang, A.; Wang, X.; Zhang, T. Green Chem. 2017, 19 (3), 638642.

${ }^{86}$ Norman, D. W. Catalytic dehydration of alcohols and ethers over a ternary mixed oxide. U.S. Patent 8,981,172B2, 2015.
${ }^{87}$ Lin, F.; Yang, Y.; Chin, Y. H. ACS Catal. 2017, 7 (10), 6909-6914.

${ }^{88}$ Lin, F.; Chin, Y. H. J. Catal. 2016, 341, 136-148.

${ }^{89}$ Yang, Y.; Lin, F.; Tran, H.; Chin, Y. H. C.

ChemCatChem 2017, 9 (2), 287-299. 